NBER WORKING PAPER SERIES

\title{
BANKS' RISK EXPOSURES
}

\author{
Juliane Begenau \\ Monika Piazzesi \\ Martin Schneider \\ Working Paper 21334 \\ http://www.nber.org/papers/w21334 \\ NATIONAL BUREAU OF ECONOMIC RESEARCH \\ 1050 Massachusetts Avenue \\ Cambridge, MA 02138 \\ July 2015
}

We thank Hui Chen, John Cochrane, Darrell Duffie, Isil Erel, Bob Hall, Lars Hansen, Anil Kashyap, Hanno Lustig, Jonathan Parker, Jean-Charles Rochet, David Scharfstein, Chris Sleet, John Taylor, Harald Uhlig and seminar participants at the 38th Annual Federal Reserve Bank of St. Louis Fall Conference, Arizona State, Chicago Booth Econometrics and Statistics Workshop, Chicago Money \& Banking, Duke, the 4th Banque de France--Bundesbank Conference in Paris, the Conference in Honor of Sargent and Sims at the Federal Reserve Bank of Minneapolis, the Conference on Expectational Coordination at the College de France, CREI, the Econometric Society Meeting in Seoul, Federal Reserve Board, the Federal Reserve Banks of Chicago, San Francisco, and New York, the "Macro Financial Modeling and Macroeconomic Fragility" Conference, NYU, MIT, Ohio State, Princeton University, the ShovenFest at Stanford, SITE, Society of Economic Dynamics in Cyprus, Stanford, Stanford Conference in Quantitative Finance, UC Davis, Yale and Wharton. The views expressed herein are those of the authors and do not necessarily reflect the views of the National Bureau of Economic Research.

NBER working papers are circulated for discussion and comment purposes. They have not been peerreviewed or been subject to the review by the NBER Board of Directors that accompanies official NBER publications.

(C) 2015 by Juliane Begenau, Monika Piazzesi, and Martin Schneider. All rights reserved. Short sections of text, not to exceed two paragraphs, may be quoted without explicit permission provided that full credit, including $(\mathcal{C}$ notice, is given to the source. 
Banks' Risk Exposures

Juliane Begenau, Monika Piazzesi, and Martin Schneider

NBER Working Paper No. 21334

July 2015

JEL No. E4,E43,E58,G0,G2,G21

\section{$\underline{\text { ABSTRACT }}$}

This paper studies U.S. banks' exposure to interest rate and credit risk. We exploit the factor structure in interest rates to represent many bank positions in terms of simple factor portfolios. This approach delivers time varying measures of exposure that are comparable across banks as well as across the business segments of an individual bank. We also propose a strategy to estimate exposure due to interest rate derivatives from regulatory data on notional and fair values together with the history of interest rates. We use the approach to document stylized facts about the recent evolution of bank risk taking.

Juliane Begenau

Harvard Business School

Baker Library 365

Boston, MA 02163

jbegenau@hbs.edu

Monika Piazzesi

Department of Economics

Stanford University

579 Serra Mall

Stanford, CA 94305-6072

and NBER

piazzesi@stanford.edu
Martin Schneider

Department of Economics

Stanford University

579 Serra Mall

Stanford, CA 94305-6072

and NBER

schneidr@stanford.edu 


\section{Introduction}

Macro-prudential policy decisions require knowledge of banks' exposures to macroeconomic risk factors. For example, how would the value of bank positions change if interest rates were to rise or credit spreads were to widen? These questions cannot be answered by a quick look at bank regulatory filings. While banks supply accounting measures for a large number of fixed income positions that differ in maturity and credit quality, those measures do not speak directly to risk exposures. For example, a bank might have a large position in high quality short-term loans that is nevertheless less affected by a change in interest rates or credit spreads than a small position in low quality long-term securities.

This paper measures banks' exposures to macroeconomic risk through their fixed income positions by representing those positions in terms of simple factor portfolios. We start from balance sheet data in the U.S. Reports on Bank Conditions and Income ("Call Reports"). We focus on two orthogonal risk factors that capture large shares of interest rate and credit risk in fixed income instruments held by banks. Both factors are portfolio returns: the interest rate factor is the return on a safe long term bond and the credit risk factor is the return on a leveraged portfolio that is long in low quality bonds. We then represent each position in a bank's balance sheet by two numbers: the dollar values of two factor portfolios that are affected in exactly the same way to the risk factors as the bank position over the next quarter.

Factor portfolios provide measures of exposure that are easy to interpret and compare across positions. $^{1}$ They can also be added up over positions or entire banks. Consider, for example, the aggregate net fixed income position (fixed income assets minus liabilities including derivatives and positions held for trading) of the U.S. banking sector at the end of 2013. We find that U.S. banks jointly held a $\$ 4$ trillion interest-rate factor portfolio. This portfolio declines in value when interest rates rise: a one standard deviation negative realization of the interest rate risk factor over Q1 2014 - that is, a typical upward shift in the level of the yield curve - would have generated a $\$ 120$ billion loss. At the same time, U.S. banks held a $\$ 3.5$ trillion credit-risk factor portfolio. This portfolio declines in value when credit spreads widen: a one standard deviation negative quarterly realization of the credit risk factor - that is, a typical increase in low quality yields that is orthogonal to the level of the yield curve - would have generated a $\$ 80$ billion loss.

We find that maturity transformation - effectively borrowing short term and lending long term - is not only a key feature of banks' traditional business (loans and deposits), but also characterizes the modern trading business of large banks, in particular their positions in interest rate derivatives.

\footnotetext{
${ }^{1}$ In the above example, the large high quality short-term loan position would be represented by small amounts in both factor portfolios, whereas the small low quality long-term securities position would be represented by larger amounts.
} 
Indeed, U.S. banks' aggregate net fixed income position at the end of 2013 was $\$ 2.3$ trillion. In terms of exposure to interest rate risk, U.S. banks thus look like a leveraged portfolio that is long $\$ 4$ trillion in the interest rate factor (that is, safe long-term bonds), but short $\$ 4$ trillion $-\$ 2.3$ trillion $=\$ 1.7$ trillion in cash (that is, a safe short bond that induces no exposure). ${ }^{2}$ Banks' interest-rate derivatives positions show a similar pattern: they look like a highly leveraged portfolio that is long $\$ 1.2$ trillion in the interest-rate factor and short $\$ 1.1$ trillion in cash. Both derivatives and other positions thus decline in value when interest rates rise.

We compute factor portfolios by position for every bank and every date in our sample. The results reveal a number of stylized facts about the evolution of bank risk taking over the last 20 years. Interest-rate risk exposure rose substantially after the repeal of the Glass-Steagall act as larger banks increasingly engaged in trading activities, including interest-rate derivatives. For large banks and those with a lot of trading business, credit risk exposure rose more slowly but then spiked to peak together with interest rate risk exposure around the financial crisis in 2008. In smaller banks and those with more traditional business, both risk exposures built up less before the crisis, but instead increased in its aftermath. This is true especially for credit risk in the loan portfolio. More generally, the cross section of banks shows considerable heterogeneity in bank risk taking as well as the role of derivatives.

Formally, our calculations proceed in two steps. We first use regressions to measure factor exposures for many fixed income instruments. This step studies only the joint distribution of returns; bank position data are not used. We consider risk exposure over a fixed horizon of one quarter. Our interest-rate risk factor is the one quarter return on a "safe bond" that reflects changes in the level of the yield curve - specifically, the return on a position in collateralized interest-rate swaps with a maturity of 5 years. Our credit risk factor is the return on a portfolio that contains the safe bond as well as a 5 year BBB rated bond, with portfolio weights chosen such that the portfolio return is conditionally uncorrelated with the safe bond return.

For a broad class of instruments with different maturity, credit quality and payoff structure, we regress returns on our two factors. To accommodate time variation in the comovement of bond returns, we run separate regressions for every date, using only observations up to that date. This is also what a regulator who applies our approach could have done in real time. For every date, the resulting regression coefficients thus provide an estimate of how much the instrument return was expected to move with each factor over the next quarter. Equivalently, they describe a simple portfolio that has the same conditional factor exposures as one dollar invested in the instrument on that date. These conclusions are robust to the possible presence of other risk factors - any

\footnotetext{
${ }^{2}$ More generally, representation of positions by factor portfolios allows us to view bank business as a leveraged "replicating" portfolio. For example, the exposures of the aggregate fixed income position to both factors looks like a leveraged portfolio that is long $\$ 4$ trillion in interest rate risk, long $\$ 3.5$ trillion in credit risk and short $\$ 5.2$ trillion in cash.
} 
such factors are subsumed in the error terms of the regressions and thus must be orthogonal to the factors we consider.

Our two factors explain a large share of variation in most instruments. For almost all maturities and credit qualities we consider, full sample $R^{2}$ s lie above $70 \%$; the exception is low quality shortterm instruments where the $R^{2}$ is about $50 \%$. The interest-rate factor alone explains the bulk of the variation in high quality instruments such as Treasuries and swaps. The credit-risk factor is instead a key driver of low quality returns. Allowing for time variation in covariances is important for capturing the change in bond price dynamics during the financial crisis. Indeed, in normal times decreases in safe interest rates make the price of all bonds increase together. What was special in 2008-9 is that risky bond prices fell while safe bond prices increased. As a result, exposure of low quality bonds to interest-rate risk actually declined during this period.

In a second step, we add bank regulatory data to derive position exposures. For securities, banks report fair values (typically market values) and provide detailed information on maturities and credit quality. We can thus directly apply instrument exposures from the first step to restate each position in terms of factor portfolios. For loans and many liabilities, we have to address the fact that banks report face values. We use information on maturity and interest rates to first express those positions as streams of future payments, and then compute factor exposures for each payment. The main results are that banks' traditional business implies positive exposure to the interest rate and credit risk factors. The former is due to holdings of securities and is concentrated more at banks that engage in market making. The latter is due to loans and is important for all banks.

A key advantage of our portfolio approach is that it is conceptually straightforward to compute exposures via derivatives positions and compare them to exposure through other business segments. After all, returns on derivative instruments are readily available and can be regressed on factors to obtain measures of exposure. To the extent that regulatory filings contain detailed data on derivatives positions, we can then infer bank exposures. The ideal data set for our purposes would contain information on market values of derivatives together with contract terms. For example, for interest rate swaps we would like to know the maturity, the locked in swap rate paid or received by the bank as well as the notional value.

Unfortunately, call report data on derivatives is limited. While banks report market values for all current positions, both positive and negative, they do not disclose the direction of trading. For example, when we observe a position with positive fair value at some date, we only know that the bank placed a bet that paid off up to that date, but not whether it was a bet on interest rate increases (e.g. a pay-fixed swap) or decreases (a pay-floating swap). Moreover, while there is some information on maturities, we do not have data on payoffs such as swap rates or futures rates that 
banks locked in the past.

To deal with the lack of reported information, we propose a Bayesian approach to estimate jointly the direction of trade and the relevant payoff information. The basic idea for identification is that if a position with positive fair value is observed right after a period of falling interest rates, then it is more likely that the bank placed a bet on falling rates. Moreover, the size of the gains on the position is informative about the difference between the current interest rate and the interest rate locked in for the same maturity in the past. Identification of the bank's strategy thus relies on the joint distribution of its net position and the history of interest rates. We also use data on bid-ask spreads and gross positions to account for the contribution of market maker rents to fair values.

Our estimation finds that most banks' interest-rate derivatives trading works like a portfolio of pay-floating swaps: banks pay their counterparty a floating rate and receive a fixed rate in return. As a result, most banks gain on their derivatives positions when interest rate rates fall so the floating rate they pay adjusts downward. In particular, we observe large gains for many banks when the Fed lowered interest rates during the 2001 recession and more recently during the financial crisis. While there is considerable heterogeneity in the use of derivatives - only about half of U.S. banks use any interest rate derivatives and the derivatives market is dominated by a few banks - we find little evidence that these positions are used to hedge other positions such as loans.

\section{Related literature}

Our approach is related to a number of alternative ways to assess bank riskiness. The regulatory framework currently being implemented is known as Basel III. Regulators ask banks to estimate default probabilities for instruments they hold either with (external) credit ratings or with internal models. ${ }^{3}$ They then determine capital requirements for each position separately. A convenient feature of our approach is that factor portfolios are additive risk measures that are comparable across positions; they could thus be used to develop risk measures for all or parts of a bank. This is an advantage over non-additive measures of risk such as VaR that are popular among some regulators (see e.g. Acharya, Pedersen, Phillipon, and Richardson 2010, Kelly, Lustig, and van Nieuwerburgh 2011 for discussions of measures of tail risk and Adrian and Boyarchenko 2012 for macroeconomic effects of VaR constraints).

Our approach is similar in spirit to the stress tests performed recently by regulators in many countries. The typical stress test posits a set of scenarios, and banks are asked to report gains or losses anticipated under each scenario (see, for example, Brunnermeier, Gorton, Krishnamurthy

\footnotetext{
${ }^{3}$ Basel II regulators also make a distinction between credit risk due to borrower default and market risk due to price changes. Our approach instead considers all risk reflected in returns. Default risk is accommodated to the extent that returns are low when there are many defaults.
} 
2012, Duffie 2012, Greenlaw, Kashyap, Shin and Schoenholtz 2012). Banks may arrive at their answers by running scenarios in their internal models. A realization of our risk factors could also taken to be a stress scenario. Of course, our calculations not only provide a single number that predicts losses in one scenario, but allows us to compute moments such as conditional volatilities. Moreover, since we provide an algorithm that goes from raw positions to bank exposures via the exposures for each instrument class, we provide a transparent way to explore where the losses in a stress scenario come from and how this depends on assumptions the distribution of fixed income returns.

There is a long tradition of relating bank performance measures to macroeconomic risk factors. One popular line of work regresses bank stock returns on a risk factor, such as an interest rate. The regression coefficient on the interest rate - often referred to as the interest-rate beta - measures the average exposure of the bank's overall value to interest rate changes over the sample period considered (Flannery and James 1984a). More recently, Landier, Sraer and Thesmar (2013) have considered alternative performance measures such as changes in interest income or earnings as a fraction of assets.

Our approach is complementary to studies based on overall performance measures. One the one hand, we only look at banks' fixed income positions. We do not capture, for example, the effect of risk factors on banks' intangible assets (for example, the bank's "franchise value") or compensation costs. Such effects would be captured by overall performance measures such as stock returns and earnings ratios, respectively. On the other hand, we proceed position-by-position and can trace out in detail how risk in banks' fixed income position is affected.

Another line of work considers average exposures in individual bank positions. One way to proceed is to directly regress position changes on candidate risk factors. Other studies first compute average exposure measures such as interest rate betas from stock return regressions and then relate those measures to summary statistics from bank positions. ${ }^{4}$ Both types of regression approaches are useful to understand average exposures over longer periods of time. ${ }^{5}$ In contrast, we are interested in how exposures change over short periods of time such as during the financial crisis; our approach delivers factor portfolios for every date in our sample.

In particular, our estimation of interest rate derivatives positions derives a time series of exposures. We build on early work by Gorton and Rosen (1995) who also infer the direction of trading from banks' positions. However, their data predates the introduction of mark-to-market

\footnotetext{
${ }^{4}$ For example, interest-rate betas have been related to banks' maturity gaps, that is, the difference between bank assets and liabilities that mature within a specified horizon (Flannery and James 1984b). Moreover, changes in bank equity values have been related to off-balance sheet statistics that indicate derivative use (Venkatachalam 1996).

${ }^{5}$ Extensions have attempted to incorporate time-varying interest rate betas, but those have proven difficult to estimate (for example, Flannery, Hammed, and Haries 1997, Hirtle 1997).
} 
accounting rules that requires banks to report cumulative gains and losses at market value. As a result, they were not able to infer time-varying exposures to interest rate risk through derivatives.

We find that banks mostly take pay-floating positions in interest-rate derivatives, which are positions that gain in value from a surprise fall in interest rates. Some of the counterparties to these positions are nonfinancial corporations, who use pay-fixed positions in swaps to insure themselves against surprising interest-rate increases. Hentschel and Kothari (2001) and Chernenko and Faulkender (2011) document these positions empirically. Jermann and Yue (2012) use a theoretical framework to study why nonfinancial corporations have a need for pay-fixed swaps.

Since the financial crisis, there has been renewed interest in documenting the balance-sheet positions of financial institutions. We share the important goal of this literature: to come up with data on positions that will inform the theoretical modeling of these institutions, as called

for by Franklin Allen in his 2001 AFA presidential address. For example, Adrian and Shin (2011) investigate the behavior of Value-at-Risk measures reported by investment banks. They document that VaR per dollar of book equity stayed constant throughout the last decade, including the financial crisis, when these institutions were deleveraging. He, Khang, and Krishnamurthy (2010) document the behavior of book values of balance sheet positions of various financial institutions.

The paper is structured as follows. Section 2 provide an overview of our approach and illustrates its benefits by showing results for a particular bank and date, JPMorgan Chase at the end of 2013. Section 3 describes the data. Section 4 provides details on the first step of our analysis, the estimation of exposures for individual fixed income instruments. Section 5 describes in detail how we represent banks fixed-income balance sheet positions. Section 6 explains our method to derive a factor portfolio representation of a bank's interest rate derivative position. Section 7 uses results for all banks to document facts on risk exposures in time series and cross section.

\section{Banks' fixed income portfolios}

This section provides an overview of our approach and a first look at the type of results it delivers. As a leading example, we consider JPMorgan Chase, the largest U.S. bank holding company. Table 1 summarizes the balance sheet in the fourth quarter of 2013 when total assets were $\$ 2.41$ trillion. It illustrates not only the importance of traditional bank business (cash, securities, and loans on the asset side, deposits and other borrowed money on the liability side), but also the bank's role as a major broker-dealer, reflected in sizeable positions in trading assets and liabilities. All numbers in the table are reported in percent of total assets.

Derivatives appear in two places in the balance sheet. On the one hand, JP Morgan Chase deals in derivatives and thus has positions of derivatives "held for trading". Those positions are 
reported as part of trading assets or liabilities if they have positive or negative market values, respectively. ${ }^{6}$ Other fixed income trading assets and liabilities include e.g. the dealer's inventory of bonds and securities lent out to clients, respectively. On the other hand, banks hold derivatives

"not for trading"; those are separately reported as part of "other" assets and liabilities.

\section{Table 1: Balance Sheet of JPMorgan Chase \& Co 2013 Q4}

(Entries are percent of total 2013 Q4 assets, $\$ 2.41$ trillion)

\begin{tabular}{|c|c|c|c|c|c|c|c|c|c|}
\hline \multirow[t]{3}{*}{ Assets } & & & & & \multicolumn{5}{|l|}{ Liabilities } \\
\hline & \multicolumn{4}{|c|}{ factor portfolios } & & \multicolumn{4}{|c|}{ factor portfolios } \\
\hline & & & credit & rest & & & rate & dit & rest \\
\hline Cash & 15 & 0 & 0 & 15 & Equity & 9 & 0 & 0 & 9 \\
\hline Fed funds + Repo & 15 & 0 & 0 & 15 & Fed funds + Repo & 7 & 0 & 0 & 7 \\
\hline Securities & 14 & 9 & 1 & 4 & Deposits & 53 & & & \\
\hline Treasury & 1 & 1 & 0 & 0 & short & 50 & 0 & 0 & 50 \\
\hline MBS & 4 & 2 & 0.3 & 1.7 & other & 3 & 0.6 & 0 & 2.4 \\
\hline other & 9 & 6 & 2.7 & 3.3 & & & & & \\
\hline Loans & 32 & 5 & 12 & 16 & Other borrowed & 15 & 5 & 0 & 10 \\
\hline \multirow[t]{2}{*}{ Trading assets } & 16 & & & & $\begin{array}{l}\text { money } \\
\text { Trading liabilities }\end{array}$ & 6 & & & \\
\hline & & & & int rate & credit & & & & \\
\hline \multicolumn{3}{|c|}{ net interest rate derivatives } & 1.2 & 17 & $0-15.8$ & & & & \\
\hline \multicolumn{3}{|c|}{ net other fixed income } & 9.4 & 8 & 1.4 & & & & \\
\hline \multicolumn{3}{|c|}{ net other trading } & -0.6 & & & & & & \\
\hline
\end{tabular}

Other assets

8

| Other liabilities $\quad 10$

A breakdown into broad categories as in Table 1 masks the large variety of instruments held by banks. Every security or loan is defined by its own stream of payment promises. Instruments differ both in the maturity of those promises and in the actual payments expected once promises come due. The value of an instrument, that is, the present value of the payment stream, thus generally depends both on the uncertain path of interest rates until maturity and on the uncertain payments. Even if the promises are fixed, the return earned holding an instrument from one date to another is subject to both interest-rate risk and credit risk.

We now outline the two steps of our analysis. We first calculate the exposure of many instruments to two key macroeconomic risk factors. We then use these instrument exposures to restate

\footnotetext{
${ }^{6}$ Some netting of positions is allowed so the total positive (negative) fair value of derivatives held for trading on the balance sheet is smaller than the total positive (negative) fair value of derivatives reported as supplementary information on schedule HC-L. Our analysis of exposures uses the latter as a starting point, as explained in detail in Section 3.
} 
bank balance sheets in terms of simple portfolios that represent those risk factors.

\subsection{Step 1: returns \& risk exposures by instrument}

We consider risk exposure over a fixed investment horizon. We ask how the value of positions responds to changes in risk factors over this horizon. In our empirical work, the horizon is one quarter. Positions with maturities shorter than this horizon are riskless and are thus treated as cash. They earn the safe interest rate which is known at the beginning of the current period. Among the positions listed in Table 1, these short positions include cash, short deposits as well as Fed funds and repo positions which all have typical maturities below one quarter. ${ }^{7}$

Consider some date $t$ and a typical bank that owns many instruments $i$ that differ in maturity and credit risk. Let the random variable $R^{i}$ describe the return from holding instrument $i$ from date $t$ on over the investment horizon. The distribution of $R^{i}$ depends on the date $t$ price of instrument $i$ as well as date $t$ expectations about its future payoff. Since prices of fixed income instruments tend to move together, the returns $R^{i}$ are typically highly correlated. Modeling risk factors is a convenient way to capture this comovement.

We study exposure to a set of risk factors that are common drivers of many returns. Let $\hat{R}^{j}$, $j=1 \ldots, F$ denote returns on particular fixed income instruments that are mutually uncorrelated conditional on date $t$ information. Without loss of generality, we write the return on instrument $i$ as

$$
R^{i}=\alpha_{i}+\sum_{j=1}^{F} \beta_{i}^{j} \hat{R}^{j}+u^{i},
$$

where $u^{i}$ is uncorrelated with all risk factors $\hat{R}^{j}$. The residual $u^{i}$ could either capture risk specific to instrument $i$, or possibly a risk factor that is not made explicit in our analysis.

The coefficient $\beta_{i}^{j}$ describes the exposure of instrument $i$ to the $j$ th risk factor: it says how much the return $R^{i}$ moves with any change in the risk factor $\hat{R}^{j}$. An equivalent interpretation is that a portfolio of one dollar invested in instrument $i$ generates the same gains or losses in response to realizations of factor $\hat{R}^{j}$ as a "factor portfolio" of $\beta_{i}^{j}$ dollars in instrument $j$. Moreover, since $u^{i}$ is orthogonal to the factors, the position of one dollar in instrument $i$ has the same factor exposures as a "replicating" portfolio that consists of $\beta_{i}^{j}$ dollars in instruments $j$ and $1-\sum_{j} \beta_{i}^{j}$ dollars in cash. In principle, any replicating portfolio weight could be negative: this would mean that the position works like a leveraged portfolio that is short in cash or one of the factors.

In our empirical work, we consider two risk factors. The first is the return on a safe zero coupon bond with maturity of five years. We use a zero coupon bond that promises the five year

\footnotetext{
${ }^{7}$ Our approach could also be used to study the risk exposures in these positions by adopting a horizon shorter than one quarter.
} 
swap rate. Since swaps are collateralized, this bond behaves similarly to a Treasury bond. Since the main driving force of bond prices is the level of the yield curve, we refer to the first factor as an interest-rate factor. Since the factor portfolio is a safe bond, positive exposure to interest-rate risk corresponds to a long position in the bond: a bank with positive exposure to interest-rate risk thus loses money when the level of the yield curve increases and safe bond prices fall. In contrast, a bank may have negative positions in interest-rate risk if it owns instruments that pay off more when the level of the yield curve increases, for example certain types of derivatives.

The second risk factor is the return on a leveraged portfolio that combines borrowing at the 5 -year swap rate with investment in higher risk BBB rated bonds. Here the leverage ratio for the portfolio is chosen so that the return is conditionally uncorrelated with the first risk factor over the investment horizon of one quarter. It thus isolates credit risk in BBB bonds that is orthogonal to interest-rate risk - we refer to the second factor as a credit-risk factor. Since the factor portfolio is driven by variation in the value of a risky BBB bond, positive exposure to credit risk corresponds to a long position in that bond: a bank with positive exposure to credit risk thus loses money when credit spreads widen so risky bond prices fall.

\section{Recursive estimation of exposures}

We run the exposure regressions (1) of returns on factors recursively: for each date $t$ we use data up to $t$. The idea here is to capture exposures observed in real time as of date $t$. Figure 1 plots regression coefficients $\beta_{i}^{j}$ (or replicating portfolio weights) using data up to the last quarter of 2013. The top and bottom panels show coefficients on the interest-rate and credit-risk factor, respectively. Each line corresponds to a credit rating, with darker lines indicating lower ratings; the line labelled Agency MBS reflects the return on an AAA rated agency MBS index. For each category, coefficients are plotted as a function of maturity, shown along the horizontal axis.

In the top panel, the orange line shows exposure to the interest-rate factor for the swap curve (that is, zero coupon bonds promising swap rates of different maturities). Since the interest-rate factor itself pays the five year swap rate, the line passes through $100 \%$ at 20 quarters. More generally, longer maturity safe bonds are more exposed to interest-rate risk than short maturity bonds: for the swap curve as well as for Treasury and high grade bonds, all lines are upward sloping.

For example, a 1-year Treasury bill is equivalent to a portfolio that puts weight $30 \%$ on the interest-rate factor and $70 \%$ on cash. In contrast, a 10-year zero coupon Treasury bond is equivalent to a leveraged portfolio that puts weight $150 \%$ on the first factor and borrows $50 \%$ in cash. Intuitively, movements in the level of the yield curve change the discounting of future fixed payoffs, with stronger effects on longer horizons. Interestingly, the line for Agency MBS is considerably flatter than for other AAA bonds because the prepayment option implicit in MBS returns make 

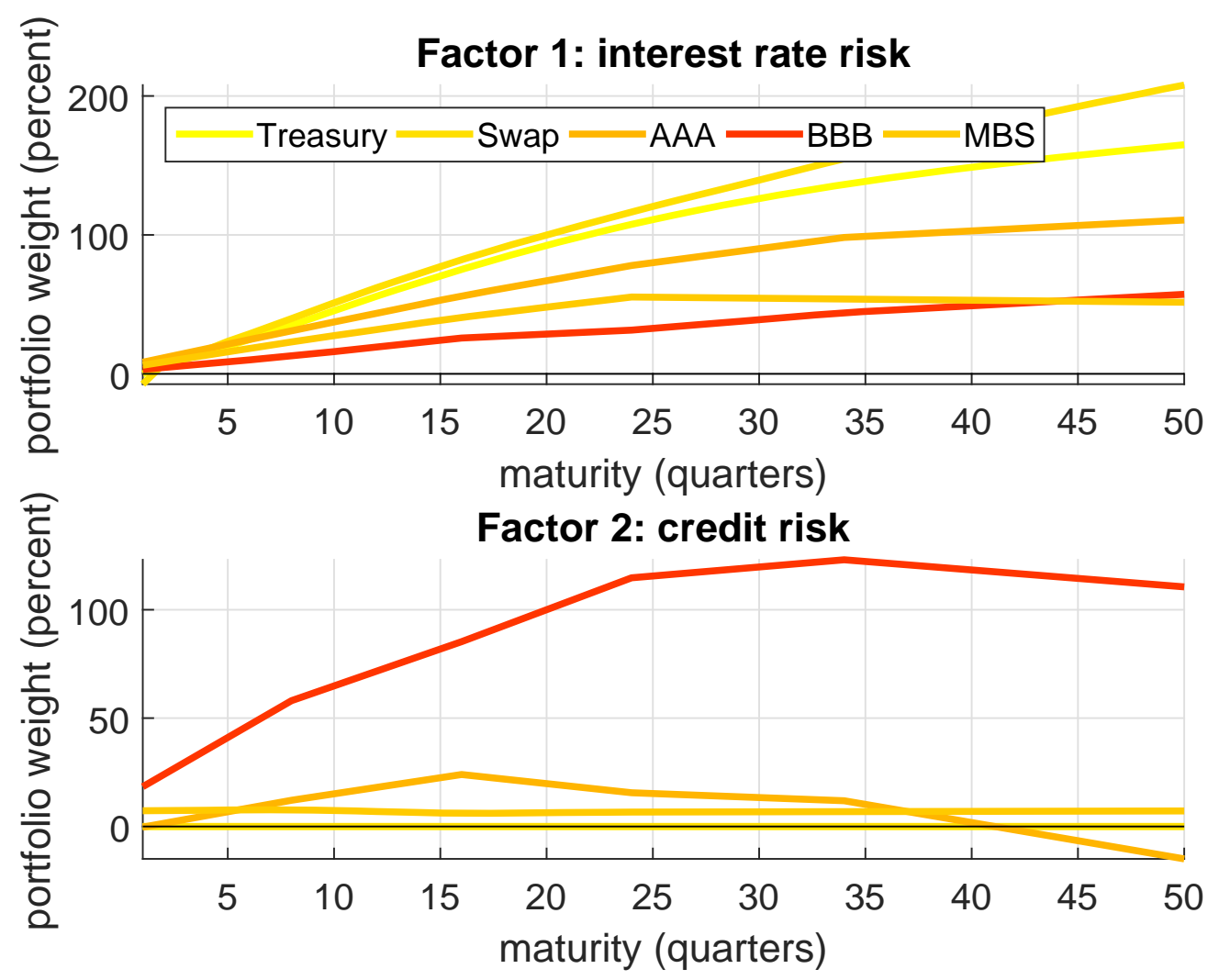

Figure 1: Top panel shows interest-rate risk exposures. Bottom panel shows credit-risk exposures. The exposures are the 2013:Q4 estimated slope coefficients $\beta_{i}^{j}$ in equation (1) on the factors $j$ for the instrument $i$ indicated in the legend and the maturity on the $\mathrm{x}$-axis.

those securities less exposed to interest-rate risk.

As credit quality worsens, exposure to interest-rate risk declines: in the top panel, darker lines are generally lower. High risk bonds even see a small negative exposure to the interest-rate factor. Intuitively, junk bonds see large price drops in recessions when the level of the yield curve falls and high quality bonds increase in value. At the same time, low quality bonds have higher exposure to the credit-risk factor: in the bottom panel, darker lines are generally higher. ${ }^{8}$ Treasuries and swaps have negligible exposure to credit risk so the brightest line effectively coincides with the horizontal axis; in fact, the 5-year swap return has zero credit risk by construction.

Our two macroeconomic risk factors explain a sizeable share of variation in returns. For 2013, the $R^{2}$ in the regressions are above 70 percent for investment grade bonds of all available maturities (BBB rated or higher) and around 90 percent for most of these maturities. For non-investment grade bonds, the $R^{2}$ for most maturities are still 50 percent and above. The interest-rate factor alone explains above 64 percent of the return variation on prime bonds of all maturities (Treasuries,

\footnotetext{
${ }^{8}$ Here the line for BBB bonds passes through $100 \%$ at 20 quarters: by construction, the second risk factor is a portfolio that has weight $100 \%$ on $\mathrm{BBB}$, is short $60 \%$ in swaps and long $60 \%$ in cash.
} 
swaps and other AAA rated bonds). We do not need to take a stand on what accounts for the remaining variation. It is possible, for example, that one can find a third factor that is generates common variation in low grade returns. Since our approach employs a linear framework with orthogonalized factors, the results are valid regardless of where the additional variation comes from, and analysis of further factor can always be added.

\subsection{Step 2: balance sheet data \& risk exposures by position}

The second step of our approach applies the regression coefficients from the first step to fixed income instruments on banks' balance sheets. Table 1 illustrates the approach with the balance sheet for JPMorgan Chase. For each position, Table 1 reports the interest-rate and credit-risk factor portfolios in the third and fourth column, respectively. For example, JPMorgan reports a securities position worth 14 percent of total assets. This position responds to realizations of the interest rate and credit risk factors exactly like interest rate and credit risk factor portfolios worth 9 percent and 1 percent of assets, respectively.

The interest rate and credit risk factor portfolio positions typically do not add up to the total reported by the bank in the balance sheet - there is also a "rest" item reported in the fifth column for each position. Since we focus on two factors, we do not take a stand on what accounts for this rest. To interpret exposures to our two factors, it is helpful to think of the rest as cash. ${ }^{9}$ For example, the securities position of JPMorgan is thus replicated by a leveraged portfolio that is short in cash and long in both factors.

The asset side of Table 1 shows key patterns that appear throughout our results below. First, banks are most exposed to interest-rate risk through their securities holdings. This is because the average maturity of securities is much longer than for loans. Second, loans are the major source of credit risk. This is because most loans receive much higher risk weights in regulatory filings than securities, many of which are government issued or at least government insured.

A third key point is that standard accounting measures (market value for securities and book value for loans) can provide misleading indications of exposures. Consider for example the exposure of Treasury bonds and MBS to interest-rate risk. While the MBS position of JPMorgan Chase was four times as large as the Treasury position in 2013, the interest-rate factor portfolio for MBS was only twice as large as that for Treasuries. An important force here is that MBS returns reflect refinancing behavior which lowers the correlation with the interest-rate factor. A related result is that the credit risk exposure due to loans is twelve times larger than that from securities, whereas in terms of total value the loan position is barely double the size of the securities position.

\footnotetext{
${ }^{9}$ This amounts to projecting the bank portfolio onto the space generated by our two factors only. Since the rest is orthogonal to those two factors, it projects into a riskless asset.
} 
The liability side of table 1 reflects exposure to the risk factors through the market value of the bank's outstanding debt. For example, an increase in the interest-rate risk factor entails an increase in bond prices which makes it more expensive (in present value terms) for the bank to service its debt. Our analysis does not take into account changes in the value of debt due to changes in the bank's probability of default. ${ }^{10}$

The bottom of table 1 reports trading assets and liabilities. Here we distinguish three categories. We have detailed information on the large positions in interest-rate derivatives, explained below. The line labelled "other fixed income trading" consists largely of the bank's inventory for market making in over the counter bond markets. Finally, "other trading" collects other items, including derivatives on credit events, foreign exchange and commodities. For those instruments, our data contain too little detail to allow an explicit analysis. ${ }^{11}$

\section{Exposure due to interest rate swaps}

For interest-rate derivatives, we report the net position recorded in the balance sheet together with the implied exposure to interest-rate risk. Since our credit-risk factor is orthogonal to the return of a bond that earns the swap rate, credit risk on collateralized swaps contracts is minimal. At the same time, exposure to interest-rate risk is large: according to our estimate, a position in interest-rate derivatives with a net fair value (that is, market value) of $1.2 \%$ of assets nevertheless implies an exposure to interest-rate risk that is equivalent to $17 \%$ worth of bonds. The reason is that interest-rate derivatives such as swaps effectively work like highly leveraged portfolios of bonds.

To provide intuition for how swap trading generates leverage and hence large exposures to interest-rate risk, consider the example of a swap, the dominant type of interest rate derivative on U.S. banks' books. A plain vanilla interest-rate swap is an agreement by two parties to exchange interest payments at regular intervals. The interest payments are proportional to a notional amount $N$. One party pays a fixed interest rate, the swap rate $s$, while the other party pays a floating short-term market rate. The payments are made at a certain frequency up to a given maturity $m$.

The stream of fixed interest-rate payments, together with the notional value paid at maturity, is referred to as the "fixed leg" of the swap. The stream of floating payments together with the notional value at maturity is called the "floating leg". Although the notional values cancel exactly,

\footnotetext{
${ }^{10}$ For large banks for which named credit default swaps are traded, it would be possible to extend our approach to take into account banks' idiosyncratic default risk. We focus here on the two major risk factors which can be easily measured so that exposure can be determined for all banks.

${ }^{11}$ The problem here is that while both credit default and foreign exchanges swap positions are likely correlated with our risk factor, their response is likely to change over time depending on what credit events are insured more (private sector or sovereign) and what currencies are traded more. While our approach could be adapted if a more detailed breakdown of positions were available, this is not possible with the data we have.
} 
including them as part of the fixed and floating leg streams is helpful in calculations.

The fixed leg is equivalent to a portfolio of bonds, specifically an $m$-period annuity that pays $s N$ per period, together with an $m$-period zero-coupon bond that pays $N$. The value of the fixed leg - the present value of the payment stream - thus depends positively on bond prices; it decreases when interest rates rise and bond prices fall. The value of the floating leg is always equal to $N$ dollars in cash. Indeed, the stream of interest payments that accrues to the owner of the floating leg is the same as the stream earned by someone who rolls over the notional at the short rate.

To see the dependence of fair values on the yield curve, consider a pay-fixed swap of maturity $m$ and notional value of one dollar that pays fixed payments at the swap rate $s$ and receives floating payments at the short (one period) rate. Let $P_{t}^{(m)}$ denote the date $t$ price of a a zero-coupon bond of maturity $m$. The fair value of the pay-fixed swap is the difference in value between the floating and fixed legs

$$
F_{t}(s, m)=1-\left(s \sum_{j=1}^{m} P_{t}^{(j)}+P_{t}^{(m)}\right) .
$$

A pay-fixed swap thus works like a leveraged portfolio that is long in cash and short in a mix of long-term bonds. A pay-floating swap does the opposite: it resembles a leveraged position in long bonds with a fair value of $-F_{t}(s, m)$ per dollar of notional value.

There is always a swap rate that makes the fair value zero - this is how the swap rate is set at inception in a frictionless market. For a given locked-in swap rate, an increase in interest rates that lowers bond prices $P_{t}^{(j)}$ also increases (decreases) the fair value of a pay fixed (floating) swap. Put differently, the fair value of a pay-fixed (or receive-floating) swap increases when rates rise since higher floating rates are then received. While pricing in over-the-counter swap markets works slightly differently due to the presence of bid-ask spreads, the same basic force drives variation in fair values.

Our quantitative results on the derivatives book of JPMorgan Chase in 2013 are typical of our findings for other banks with large broker-dealer operations. We find evidence of pay-floating positions that produced gains in value when interest rate fell. Since banks' traditional business also tends to be long in long-maturity bonds and short in cash, the exposure to interest-rate risk due to market making and other business goes in the same direction. Rather than hedge exposures from other business, the derivatives book tends to also bet on falling interest rates.

\section{Data}

This section describes data on bank positions and interest rates used in our analysis. 


\section{Bank call reports}

Our bank balance sheet data come from the "Call Reports". That is, quarterly regulatory filings that banks operating in the United States provide to their regulatory supervisor. Call reports are filed by both bank holding companies (BHCs submit form FR-Y-9C) and commercial banks (form FFIEC 031 and 041). A commercial bank is often owned by a BHC and a BHC itself can be a subsidiary of a larger BHC. We consider only BHCs that are the "top tier" company in their BHC, and eliminate any BHC that is owned by another BHC. We also eliminate all BHC that have a foreign parent. Finally, we exclude from our analysis the two large investment banks Goldman Sachs and Morgan Stanley that became BHCs only recently in the wake of the financial crisis. Apart from these two, our analysis considers all domestic top-tier bank holding companies during 1995:Q1-2014:Q2.

Some information, such as the maturity distribution of a bank's loan and securities portfolio, is only reported by commercial banks. In this case we aggregate the relevant commercial banking data for all commercial banks that belong to the same top-tier BHC. We also use information on merger and acquisition activities over our sample from the Federal Reserve Bank of Chicago. This database contains the date of a merger, the identity number of the non-surviving and the acquiring bank and their respective $\mathrm{BHC}$ identity number. Information on mergers is relevant when we estimate banks' exposure via loan and derivatives positions; for those positions available information on market value at a point in time is not sufficiently detailed and we use the bank's history to inform our inference.

Size of Banks

The FR-Y-9C forms are prepared by banks that have at least $\$ 500$ million worth of assets. ${ }^{12}$ The banking sector is highly concentrated. At the end of 2013, the median BHC's asset size was $\$ 1$ billion, while the top one percentile BHC's asset size was at least $\$ 297$ billion. The smallest top 10 bank held $\$ 364$ billion assets, while the largest bank (JPMorgan Chase) held $\$ 2.41$ trillion. Together the top 10 banks held 68 percent of the assets in the entire market.

Balance sheet positions $\&$ accounting rules

Table 1 shows the classes of positions on the balance sheet of a modern bank, here JPMorgan Chase. Positions in cash as well as fed funds sold and repurchase agreements (that is, unsecured or collateralized short term lending) mature in less than one quarter. We have data on the maturity distribution of loans, securities, deposits, and other borrowed money. Moreover, we have data on the maturity distribution of interest-rate derivatives.

A bank can hold loans and securities "for trading" or "not for trading", resulting in different

\footnotetext{
${ }^{12}$ Smaller banks report biannually in form FR-Y-9SP. They are oftentimes owned by a larger BHC and therefore accounted for by the consolidated top-tier BHC report.
} 
accounting treatment. Until the 1980s, all loans and securities were recorded on balance sheets at face value. For example, for the typical installment loan, the face value is the amount of money disbursed when the loan is taken out. For the typical coupon bond, the face value is the amount repaid at maturity. Over our sample, however, General Accepted Accounting Principles (U.S. GAAP rules) moved towards mark-to-market accounting under which position are reported at fair value, that is, the resale value of the instrument at current market prices.

Mark-to-market accounting is encouraged by the Financial Accounting Standard Board. In particular, statement FAS 115, issued in 1993, introduced a three way split of loan and securities positions into "held to maturity", "available for sale", and "held for trading" instruments. The first category is for debt instruments that banks intend to hold until they mature. These instruments are recorded at face value or amortized costs on the balance sheet. The latter two categories are recorded at fair value and comprise instruments that banks intend to hold only for a short amount of time. ${ }^{13}$ The call reports provide a breakdown into the three categories for both loans and securities. ${ }^{14}$

Securities are recorded at fair value in case they are available for sale and amortized cost in case they are held until maturity. Additionally, banks are asked to provide information on the fair value of securities held to maturity. We therefore have fair values for all securities, and our approach takes these fair values as the key input. In contrast, the majority of loan positions over our sample is recorded at face value. Banks also provide information on face values for those loans reported at fair value. We therefore have face values for all loans, which is the input for our approach. For deposits and other borrowed money (that is, other debt such as commercial paper) banks also report face value, and this is what we use as input.

Maturity $\&$ credit risk

Call reports provide detailed information on positions within broad loan and securities categories. We are especially interested in two dimensions: maturity and credit quality. The former matters for exposure to interest-rate risk, while the latter is key for exposure to credit risk. By maturity, we mean throughout the time until repricing. For example, a 15 year floating-rate mortgage for which the rate will be reset in 1 year has maturity of 1 year rather than 15 years. This concept of maturity is appropriate for studying risk exposure: since the payoffs of the instrument can change after one year to reflect shocks to interest rates or credit quality, the exposure of a floating-rate mortgage is effectively the same as that of a one year mortgage.

\footnotetext{
${ }^{13}$ The difference between available for sale and held for trading assets is how changes in fair values affect earnings. Trading gains and losses directly affect net income, whereas gains and losses on available for sale assets enter other comprehensive income, a component of equity.

${ }^{14}$ Trading liabilities are mostly derivatives with a negative fair value. Trading liabilities also arise from short selling securities.
} 
Positions on securities and loans broken down by maturity are available from the call reports for commercial banks. Banks report categories of instruments with maturities sorted into five buckets: maturities less than one quarter, 1-4 quarters, 1-3 years, 3-5 years, 5-15 years and more than 15 years. To use this information, we match commercial banks to their top tier parent BHC. We then aggregate positions over all commercial banks with the same parent. The total positions from commercial bank files and BHC files are consistent for most banks. Positions on maturities for deposits (schedule HC-E memoranda), other borrowed money (schedule HC-M), as well as interest-rate derivatives (schedule HC-R) and credit derivatives (schedules HC-R and HC-L) are available for all BHCs.

For loans, the assignment to a particular maturity bucket depends on whether the bank receives a fixed or a floating rate payment. For fixed rate loans, the assignment to a maturity bucket depends on the remaining maturity of the loan. For floating rate loans, it depends on the next repricing date. The repricing date is adjusted when a loan is expected to be prepaid. Occasionally, BHCs do not match with a commercial banks and therefore we do not have information on the loans and securities maturity distribution for that bank. For these BHCs, we use the aggregate loans and securities maturity distribution in our computations.

Figure 2 shows banks' holdings of securities in the left panel and loans in the right panel. In this and further figures below, the total for securities also contains securities held for trading. The total amount of security holdings and loans has increased over time. During the 1990s, holdings of securities were roughly equally distributed across maturities. During the years 2001-2007, when interest rates increased, holdings of securities have become more long term. Most recently, their maturity shortened again. Loans also became more long term over time. For example, the maturity of commercial loans has increased (except during the recent recessions, from the E.2 release by the Board of Governors of the Federal Reserve System.)

BHCs provide information on credit risk from which regulators calculate risk-weighted capital requirements. Both loans and securities can have risk weights of zero, 20\%, 50\%, or 100\%. Since 2001, there is also information on instruments with $200 \%$ risk weight; however, it is reported together with instruments in the $100 \%$ risk weight category. Risk weights are reported separately for securities held for trading.

Risk weights categories can be mapped into groups of credit ratings provided by the major rating agencies. In particular, we use the regulatory guidelines in the instructions for schedule HC-R (regulatory capital) that informs banks how to map credit rated securities to risk-weighted securities. We assign assets with a risk weight of zero to Treasuries. We assign assets with a risk-weight of $20 \%$ to AAA rated securities, assets with a risk-weight of $50 \%$ to A rated securities, and finally assets with a risk weight of at least 100\% to BBB rated securities. 


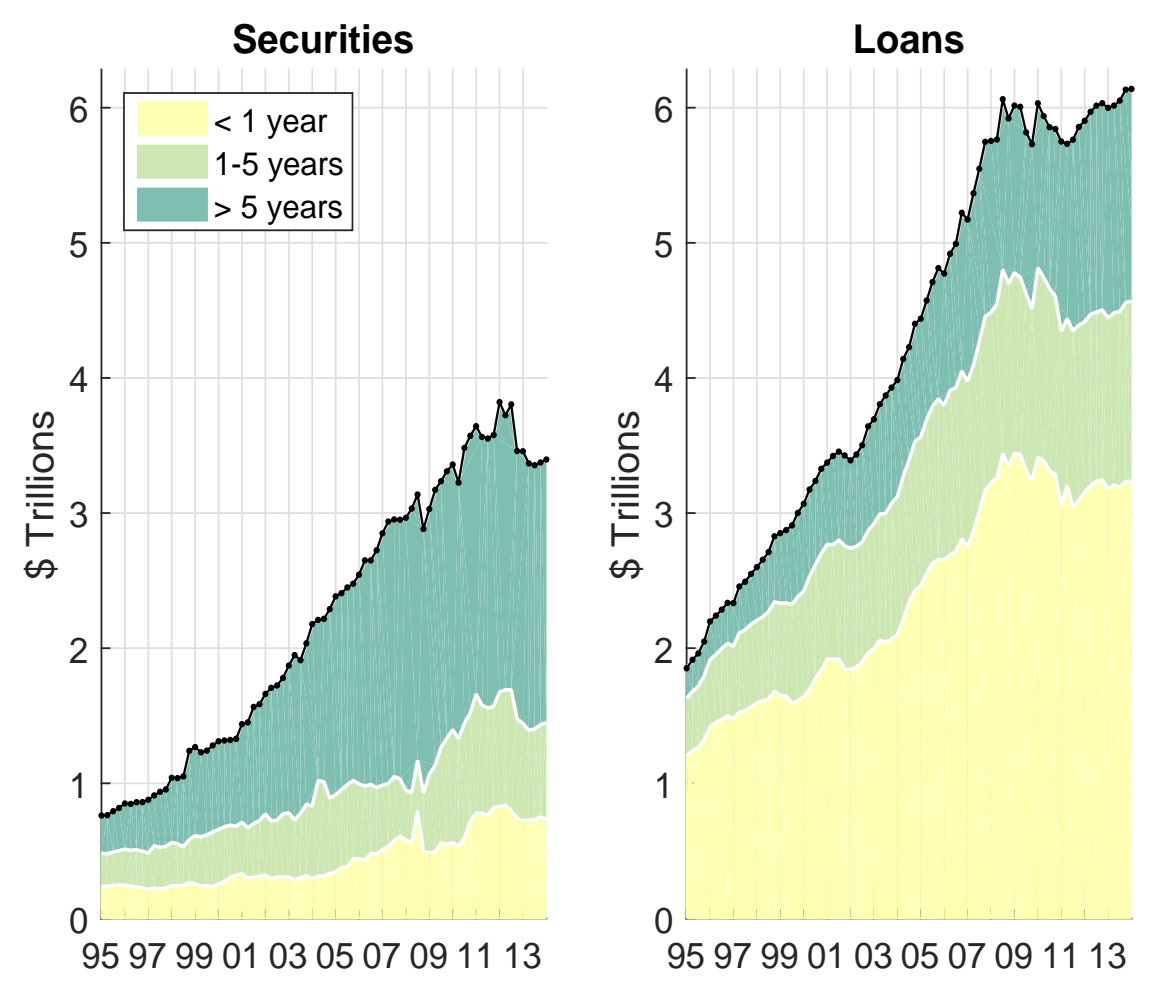

Figure 2: Holdings of aggregate U.S. banking sector by maturity bucket. Left panel: market value of securities. Right panel: face value of loans.

In addition to risk weights, banks report shares of securities issued by the government as well as mortgage-backed securities guaranteed by government-sponsored enterprises (GSEs). Figure 3 presents the risk classes for securities (left panel) and loans (right panel). Since 2000, the share of risky loans and securities has increased, whereas investments in low risk securities such as Treasuries has remained constant until the crisis. High risk securities, with a risk weight of at least 100\%, and agency MBS securities have been on a rise between 2000 and 2007. During the financial crisis, the share of liquid securities such as Treasury securities and agency MBS increased. Banks' loan portfolio consists mostly of high risk loans (with a risk weight of at least 100\%) whose loan portfolio share has been increasing over our sample period. Since the crisis, the totals for securities and loans have leveled off.

\section{Accounting for derivatives}

Statement FAS 133, issued in 1998, requires that all derivatives are carried on the balance sheet at fair value. The call reports also distinguish between derivatives "held for trading purposes" or "not held for trading". As for loans and securities, the difference is in how changes in market values affect income. However, the meaning of "held for trading" is broader for derivatives than for loans and securities and does not only cover short-term holdings. ${ }^{15}$

\footnotetext{
${ }^{15}$ The broad scope of the term "held for trading" is clarified in the Federal Reserve Board's Guide to the BHC
} 

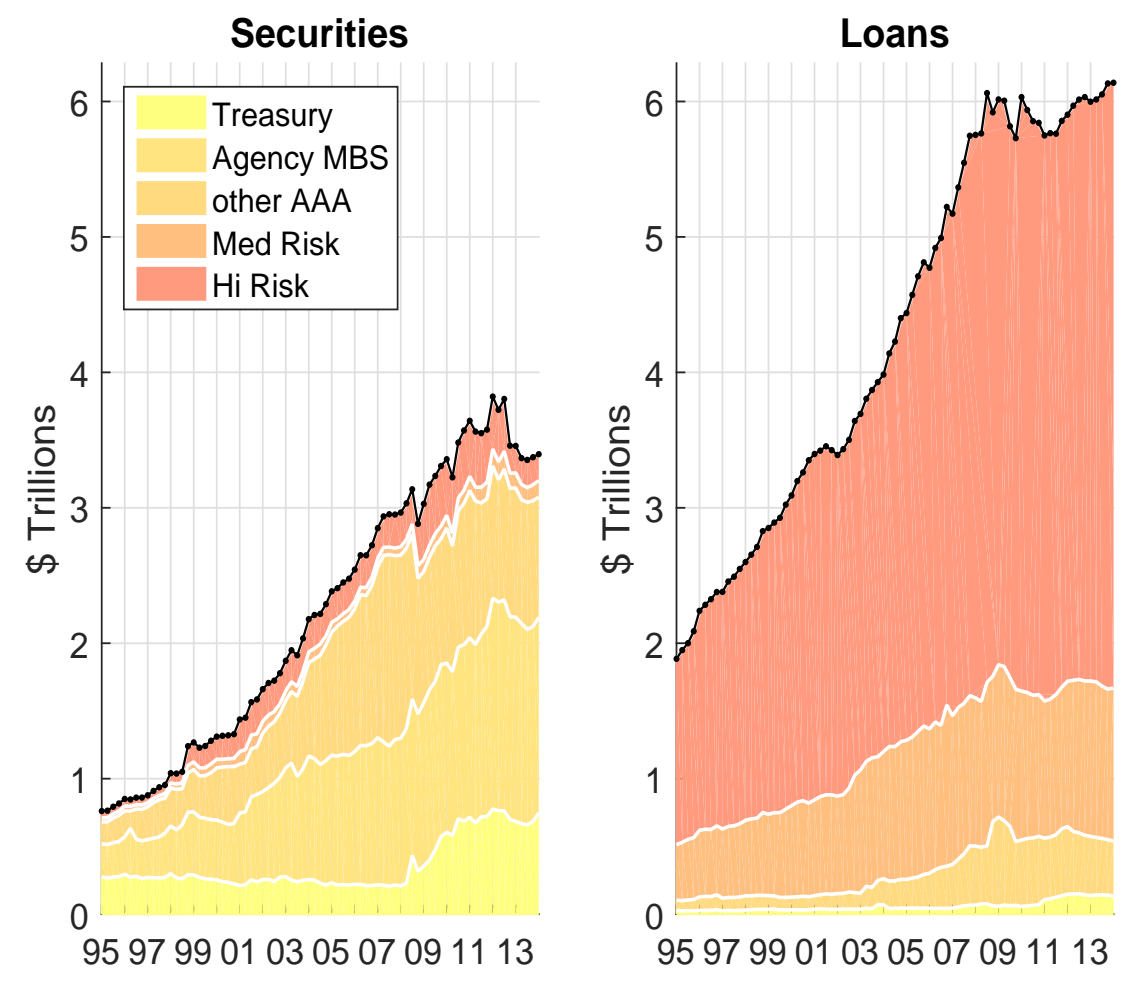

Figure 3: Holdings of aggregate U.S. banking sector by risk class. Left panel: market value of securities. Right panel: face value of loans.

Schedule HC-L of the call reports provides both fair values and notional values for derivatives by type of exposure (for example, interest rate, credit, or foreign exchange). Banks compute, for every derivative position, whether its fair value is positive or negative. Positions with positive (negative) fair value add to the total gross positive (negative) fair value. In particular, if the bank has intermediated a trade and holds a positive position with one customer that is offset by a negative position with another customer, then this activity is reflected in the gross fair values. Positions within one BHC have to be reported on a consolidated basis.

For derivatives that are reported on balance sheet (under trading assets), banks can apply so called master netting agreements under which derivatives are typically traded. These agreements stipulate the conditions that allow banks to net obligations from several contracts against one specific counterparty. This allows banks to report only the net-exposure per counter-party on balance sheet as long as the master netting agreement applies. ${ }^{16}$

performance report: "Besides derivative instruments used in dealing and other trading activities, this line item (namely, derivatives held for trading purposes) covers activities in which the BHC acquires or takes derivatives positions for sale in the near term or with the intent to resell (or repurchase) in order to profit from short-term price movements, accommodate customers' needs, or hedge trading activities". In contrast, derivatives "not held for trading" comprise all other positions.

${ }^{16}$ This is a key difference to European reporting standards that allow for significantly less netting of derivative contracts. 
A key limitation of call report data on interest-rate derivatives is that banks need not report the direction of trading. For example, while we know the net fair value of interest rate swaps, we do not know whether this fair value reflects cumulative gains or losses from pay-fixed or pay-floating swaps held by the bank. Our estimation approach below uses bank positions together with the history of interest rates to infer the direction of trading. In contrast, the call reports are explicit about the direction of trading in the case of credit default swaps. Banks need to report notionals and gross fair values for credit default swaps in which case banks sold and bought protection.

A further limitation of current accounting rules is that call reports cannot be used to easily distinguish hedging, speculation and intermediation. In particular, there is no clean mapping between "held for trading" and short term holdings due to intermediation or short term speculation. Similarly, there is no clean mapping between "not held for trading" and hedging. ${ }^{17}$ On the one hand, "held for trading" derivatives could contain long-term speculative holdings, but also hedges, in principle even qualifying accounting hedges. On the other hand, derivatives "not held for trading" could contain speculative holdings, as long as they are not short term.

Moreover, both swaps remain in the accounts of the dealer and contribute to the reported numbers for notional and fair values. The income on the swap is earned only period by period as the swap payments are made and are recorded as income when they are received. ${ }^{18}$

Figure 4 shows the notionals for interest-rate derivatives in the left panel and their maturities on the right panel. The left panel illustrates that the trading of interest-rate derivatives started in the mid 1990s and increased dramatically until the financial crisis. Today, their total notionals are huge, above 150 trillion Dollars. Most of these derivatives are for trading; the small share of notionals that are not for trading is the small light blue slice at the bottom of the notionals in the left panel. As for many classes of bonds, a few large dealers make the market, and there is a large amount of interdealer trading. The concentration of the derivative market is illustrated by the large dark blue slice of notionals in the left panel. These notionals are held by the four BHCs with the largest holdings of interest-rate derivatives. The tiny pink slice of "other" notionals are

\footnotetext{
${ }^{17}$ Independently of whether a derivative is designated as "for trading", FAS 133 provides rules for so-called hedge accounting. The idea is to allow businesses to shelter earnings from changes in the fair value of a derivative that is used to hedge an existing position (a "fair value hedge") or an anticipated future cash flow (a "cash flow hedge"). In both cases, there are stringent requirement for demonstrating the correlation between the hedging instrument and the risk to be hedged. If the derivative qualifies as a "fair value hedge", then the fair value on the hedged position may be adjusted to offset the change in fair value of the derivative. This is useful if the hedged position is not itself marked to market, for example if it is fixed rate debt and the derivatives is a pay-floating swap. If the derivative qualifies as a "cash flow hedge", then a change in its fair value can initially be recorded in OCI, with a later adjustment to earnings when the hedged cash flow materializes.

${ }^{18}$ Swap dealing and bond dealing therefore affect a dealer's position rather differently. A bond dealer makes the market by buying and selling bonds. He makes money because he buys at a lower bid price and sells at a higher ask price. The inventory of bonds currently held is recorded on the dealer's books as trading assets (or trading liabilities if the dealer allows a short sale). Once the dealer sells a bond, it is no longer on the dealer's balance sheet. The bid-ask spread enters as income once it is earned.
} 

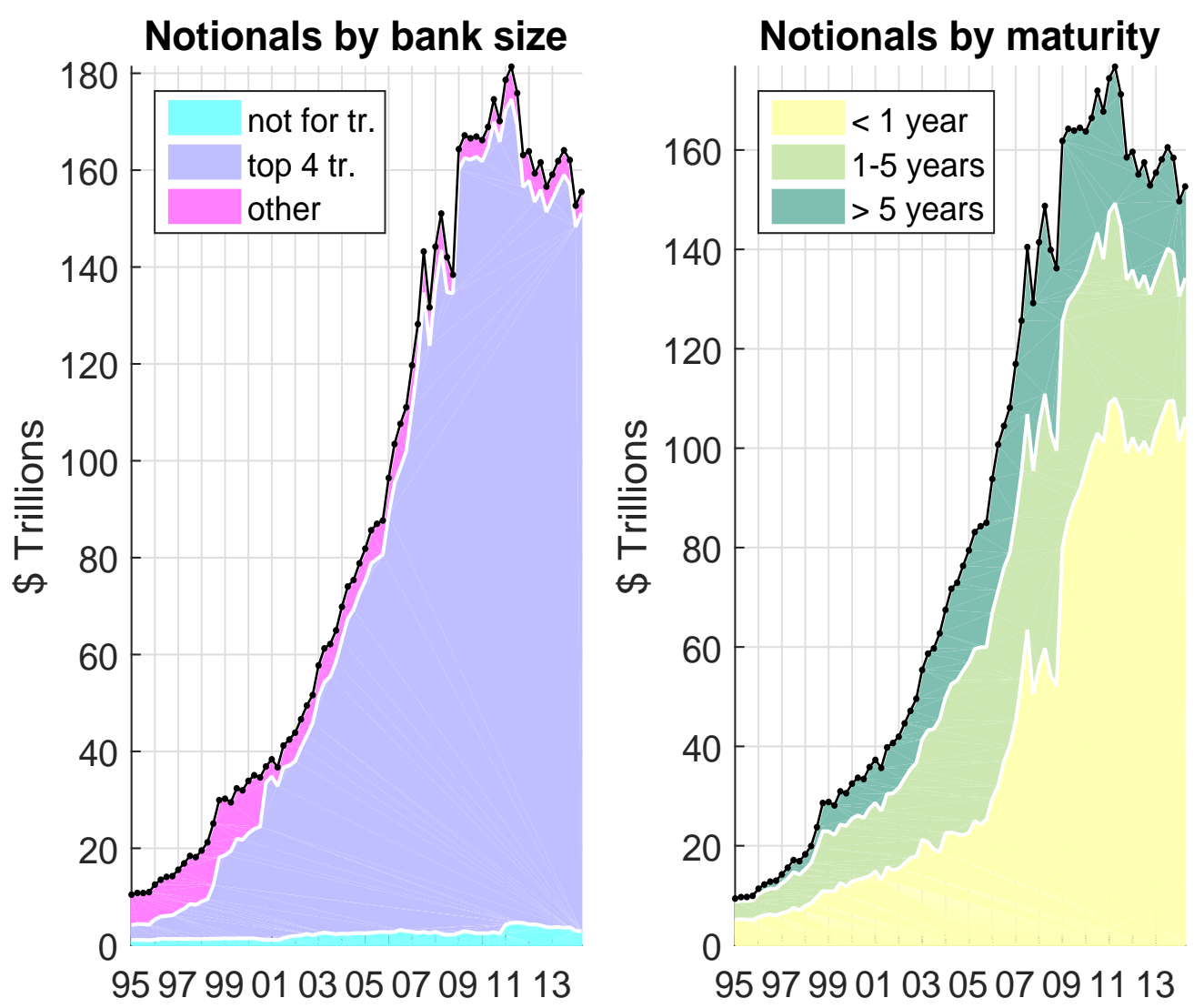

Figure 4: Notionals of interest rate derivatives for aggregate U.S. banking sector. Left panel: notionals not for trading (light blue) for trading held by top 4 BHCs (purple), other (pink). Right panel: notionals by maaturity bucket.

held by the other banks.

The right panel of Figure 4 shows a similar maturity pattern as for loans in Figure 2. The maturity of derivatives lengthened during the years 2001-2007 as interest rates increased and then shortened somewhat after the crisis.

\section{Returns}

We collect data on returns from various fixed income securities and run exposure regressions (1) for every quarter $t$ in our sample, 1990:Q2 to 2014:Q2.

The returns on Treasuries and swaps are computed from price data. The data for Treasuries for all maturities are from the Federal Reserve Board website. The source of all other return data is Bloomberg. LIBOR has maturities three and six months. Swaps have annual maturities between 1 and 10 years, then 12, 15, 20, 25, and 30 years. The returns on risky bonds are by 
credit quality: AAA, AA, A, BBB, BB, B and C+. For each credit quality, Bank of America Merrill Lynch provides a "total return index" that tracks the actual return on a bond investment for various maturity buckets (years 1-3, 3-5, 5-7, 7-10, 10-15 and 15+ years). The returns data on mortgage-backed securities have the same maturity buckets, with a few missing observations for intermediate maturities, and are also constructed by BofA Merrill Lynch.

Table 2 reports statistics associated with the returns $R^{i}$ where $i$ indicates the instrument in the first column and its maturity in the second column. The third column reports the mean returns, while the fourth column reports their volatility over the entire sample. The broad pattern is that longer maturity bonds of the same credit quality have returns that are higher on average and that are more volatile. For example, Treasury bonds, swap bonds and AAA rated bonds with short maturities (1-3 years) have returns that are roughly 5 percent per year on average with a 3 percent volatility. Bonds with medium maturity (5-7 years) and long maturities (10-15 years) have mean returns that are each 2 percentage points higher. The return volatility for longer maturity bonds is also higher, between 6 and 14 percent. The mortgage-backed securities are comparable to these highly rated bonds, as their returns have similar properties. Holding maturity constant, lower credit-quality bonds have returns that are on average higher (roughly two percentage points higher) and more volatile than higher quality bonds (between 3 and 23 percent).

Our interest-rate factor is the return on the 5-year bond of swap quality. To construct our second factor, we regress the BBB return on a constant and the first factor. The residual from this regression is our credit-risk factor. Figure 1 plots the recursively estimated risk exposures to these factors for many instruments. To understand the return variation explained by these exposure regressions, Table 2 reports results of the same regressions in columns 5-9 but now for the entire sample. Highly rated bonds (such as Treasuries, swaps, and AAA bonds) have positive exposures to the interest-rate factor. When the 5-year swap rate falls, the price of the swap bond appreciates and its return is positive. During times with falling safe rates, other high-quality bonds also appreciate because their (almost certain) payoffs are discounted less and thus they experience positive returns. Since all high-quality bonds comove strongly, the regression coefficient is one for medium bond maturities. In other words, high quality bonds with medium maturities experience roughly the same return as the 5-year swap bond. The estimated slope coefficients are monotonic in the maturity of the bond $i$ that is being considered. As 5-year swap rates fall, short bonds appreciate less percentage wise than medium bonds, leading to a $30 \%$ coefficient, while the percentage increase in long bonds is twice as large. The estimated coefficients are all highly significant. The t-stats in column 6 are all well above two.

Lower quality bonds are less exposed to the interest-rate factor. The estimated coefficients for BBB bonds are between 0.13 and 0.57. For C+ bonds, the estimated coefficients even switch sign and turn negative. The intuition behind this lower exposure is as follows. When safe interest 
rates fall, fixed payoffs are discounted less, which tends to push up their valuations. However, safe rates tend to fall in recessions, which are times when default probabilities increase and risky bonds are less likely to pay off. This increase in credit risk reduces the impact of falling safe rates on the interest rates on credit risky bonds and their prices increase by less. For bonds with very low credit ratings, the effect on credit risk dominates and their rates increase.

Mortgage backed securities are also less exposed to the interest-rate factor than safe bonds, with estimated coefficients between 0.23 and 1 . There are two reasons. First, there is some default risk in mortgages, as with lower quality bonds. The second reason is the prepayment option. When safe interest rates fall, homeowners prepay their outstanding mortgages and refinance into cheaper mortgage contracts that feature the new lower rates. This prepayment lowers the value of the mortgage backed securities. Both reasons counteract any simple increase in present values of fixed payoffs due to lower safe rates.

Highly rated bonds are almost not exposed to the second factor, which represents credit risk. The estimated slope coefficients in column 7 are small for Treasuries, swaps and AAA bonds, and most coefficients are not significant (with t-stats below 2). The coefficients are estimated to be much higher for lower quality bonds. For example, the slope coefficient is between 0.6 and 1.1 for BBB-rated bonds, monotonically increasing in maturity. The coefficients for $\mathrm{C}+$ rated bonds are between 1.6 and 3.5. These coefficients are highly significant.

The $R^{2}$ s in column 9 with two risk factors are high. Most of them are above $70 \%$, except for the $\mathrm{C}+$ rated bonds. The high $R^{2}$ s indicate that two factors do a good job at capturing the variation in our returns data.

The last column reports the $R^{2}$ s in regressions with only the first factor as regressor. This factor model works well for highly rated bonds, where the risk in safe interest rates explains more than 64 percent of the variation. As we move down the rows of the last column, we see that interest-rate risk not capture the return variation for lower quality bonds very well. The $R^{2} \mathrm{~s}$ for $\mathrm{BBB}$ and $\mathrm{C}+$ rated bonds are around 10 percent.

Our computation of exposures regresses returns data on risk factors. Alternatively, we have computed these exposure coefficients from arbitrage-free affine term structure models for safe and credit risky bonds in previous drafts of this paper. The solution for log returns in these models is also linear (or affine) in the factors. There are several advantages of using linear regressions over an arbitrage-free model. First, the model requires assumptions on loss in default and default probabilities for credit risky bonds. Similarly, the prepayment option for mortgages does not lead to tractable model solutions for MBS returns. Finally, the model needs to specify the complete set of factors that affect factors together with the distribution of their innovations. By using returns data and orthogonalized factors, these aspects are all addressed in regressions. Of course, 
arbitrage-free models impose more cross-equation restrictions which often help in getting more precise estimates for exposures. In our application, we felt that precision was not a problem (considering the high t-stats in Table 2).

\section{Table 2: Exposure Regressions}

\begin{tabular}{llrrrrrrrr} 
& & $\begin{array}{c}\text { mean } \\
\text { (in \%) }\end{array}$ & $\begin{array}{c}\text { vol } \\
\text { (in \%) }\end{array}$ & $\beta^{\mathrm{INT}}$ & t-stat & $\beta^{\mathrm{CR}}$ & t-stat & $R^{2}$ & $\begin{array}{c}R^{2} / \mathrm{w} \\
\text { factor }\end{array}$ \\
\hline Treasuries & short & 4.9 & 2.7 & 0.35 & 17.6 & 0.00 & 0.0 & 0.77 & 0.77 \\
& medium & 7.3 & 6.8 & 1.08 & 37.0 & -0.03 & -0.6 & 0.96 & 0.95 \\
& long & 9.2 & 12.0 & 1.64 & 15.9 & -0.18 & -1.5 & 0.70 & 0.70 \\
Swaps & short & 5.4 & 3.0 & 0.40 & 21.6 & 0.02 & 0.9 & 0.81 & 0.81 \\
& medium & 7.7 & 7.3 & 1.16 & 131.3 & -0.03 & -2.5 & 1.00 & 0.99 \\
& long & 9.7 & 13.3 & 2.07 & 29.8 & -0.29 & -4.0 & 0.90 & 0.89 \\
\multirow{4}{*}{ AAA } & & & & & & & & & \\
& short & 5.2 & 2.3 & 0.31 & 15.2 & 0.12 & 2.3 & 0.70 & 0.64 \\
& medium & 7.1 & 5.3 & 0.78 & 27.4 & 0.16 & 1.7 & 0.80 & 0.78 \\
& long & 7.6 & 8.0 & 1.10 & 15.2 & -0.14 & -0.9 & 0.69 & 0.68 \\
BBB & short & 5.9 & 3.0 & 0.13 & 6.5 & 0.58 & 15.4 & 0.87 & 0.07 \\
& medium & 7.7 & 5.7 & 0.31 & 28.5 & 1.15 & 110.7 & 0.99 & 0.11 \\
& long & 8.6 & 6.6 & 0.57 & 15.5 & 1.11 & 21.8 & 0.90 & 0.27 \\
C+ & & & & & & & & & \\
& short & 8.5 & 13.8 & -0.54 & -2.3 & 1.57 & 5.7 & 0.46 & 0.11 \\
& medium & 9.6 & 17.7 & -0.97 & -5.8 & 2.99 & 20.1 & 0.74 & 0.11 \\
& long & 10.6 & 22.5 & -2.27 & -2.2 & 3.53 & 4.2 & 0.60 & 0.17 \\
MBS & short & 4.9 & 1.8 & 0.23 & 7.9 & 0.08 & 3.3 & 0.56 & 0.52 \\
& medium & 5.6 & 3.4 & 0.54 & 11.8 & 0.55 & 1.0 & 0.79 & 0.78 \\
& long & 6.4 & 4.8 & 0.99 & 15.0 & 0.94 & 0.9 & 0.89 & 0.87
\end{tabular}

Note: The sample is quarterly data from 1990:Q2 to 2014:Q2. Columns 1 and 2 of this table indicate the instrument that is being considered. "Short" refers to maturities between 1 and 3 years, "medium" refers to 5-7 years, and "long" to 10-15 years. For instruments like Treasuries where we have all maturities, we average the returns on bonds for those maturities. For others, such as risky bonds with a certain rating ,Bank of America Merrill Lynch provides the return data for these maturities. Columns 3 and 4 report the mean return and its standard deviation per year. Columns 5-9 report the results from exposure regressions

$$
R_{t}^{i}=\alpha_{i}+\beta_{i}^{\mathrm{INT}} R_{t}^{\mathrm{INT}}+\beta_{i}^{\mathrm{CR}} R_{t}^{\mathrm{CR}}+u_{t}^{i}
$$

where $R_{t}^{\mathrm{INT}}$ is the interest-rate factor and $R_{t}^{\mathrm{CR}}$ is the credit risk factor based on the entire sample. The interest rate factor is the return on a 5-year swap bond. The credit 
risk factor is the orthogonalized return on a 5-year BBB rated bond; it is defined as the residual from a regression of the $\mathrm{BBB}$ rated bond on a constant and the interest rate factor. Column 10 reports the $R^{2}$ from regressions on only the interest-rate factor based on the entire sample.

\subsection{Time variation in factor exposures by instrument}

Figure 5 shows the evolution of factor exposures (or replication weights) over time for instruments in two risk classes. The top left panel describes the interest-rate risk exposure of Treasury securities and loans with zero risk weight. The top and bottom panels in the right column consider exposure of $\mathrm{BBB}$ securities and loans with $90 \%$ risk weight. In each of these three panels, exposures are plotted for maturities from 1 to 60 quarters as a function of calendar time; darker lines represent longer maturities. A general pattern across panels is that darker lines are close together while lighter lines tend to be further apart. This reflects the familiar fact that longer maturity bonds tend to be relatively close substitutes.

The bottom left panel shows the conditional volatilities of the two factor returns. ${ }^{19}$ It reveals a stark contrast in the behavior of the two risk factors. The volatility of interest-rate risk settles down at around $3 \%$ per quarter, after a brief initial transition period. In contrast, the volatility of credit risk increases throughout the sample, and in particular takes two steps up: a smaller one right after the 2001 recession and a second, larger one during the buildup of the financial crisis. This last fact is important for interpreting the changes in factor exposures. For example, even if the dollar amount in the credit-risk factor portfolio remains relatively constant over time, the typical gain or loss due to a standard deviation return innovation can move around substantially.

The top left panel shows how the exposure of safe instruments to interest-rate risk changes over time. For short maturities, exposures are close to constant. In contrast, long bonds have become substantially more exposed since the financial crisis. Our recursive estimation picks up the unusually large increases in long term bond prices when the level of the yield curve dropped in 2008-9. Those movements are often interpreted as an increase in the demand for safe long bonds (or a decrease in the risk premium on such bonds). Interestingly, the pattern is not present around the 2001 recession - it is unique to the aftermath of the financial crisis.

The black solid and dotted lines show the average exposure of the security and loan portfolio of the aggregate U.S. banking sector, respectively. Since loans are relatively short term, as apparent already in Figure 2, the average exposure resembles that of a fairly short bond. As banks increase their loan maturity gradually, the dotted line crosses several lighter lines and then resembles a

\footnotetext{
${ }^{19}$ From the layout of the figure, one might expect in this panel weights on the credit risk factor for Treasury bonds. However, by construction of our factors, credit risk in Treasury bonds is negligible and therefore those weights are not shown.
} 
somewhat longer maturity bond. Since maturity is short, exposure respond little after the financial crisis. Since securities have longer maturities, there is a marked increase in exposures after 2008, although it is tampered somewhat by banks' shortening their portfolios.

The top right panel shows how high risk instruments were exposed to interest-rate risk. Here a key observation is that exposures of medium and long bonds drop in recessions. This is already the case for 2001, and appears even more dramatically after the financial crisis. Interestingly, in the latter period the drop in exposures extends to much shorter maturities as well. The intuition here is that in recessions credit-risky bond prices fall (and spreads are high) even though the Fed lowers interest rates. This phenomenon is quite different from the dynamics in normal times, when lower safe interest rates go along with higher bond prices. It is important for this result to have a model with time varying correlations that can pick up the difference covariance structure (and hence exposures) that is relevant in recessions.

The bottom right panel reports exposures of high risk instruments to credit risk. An interesting pattern here is that while medium and long term instruments retain similar exposures over time, the exposure of shorter term bonds increases, especially after the financial crisis. This shift is also reflected in the exposure of banks' loan portfolios which increases substantially. At the same time, both loan and securities portfolios become less exposed to interest-rate risk in the aftermath of the financial crisis, as reflected in the black lines in the top right panel.

The recursive estimation of exposures can easily deal with the downweighing of past data. We have implemented various versions of constant gains estimations along these lines. For a wide range of forget parameters, one-sided (or backward looking) estimations give results that are quite comparable to the results presented here. Two-sided estimations that weigh observations both in the past as well as in the future give more different results; they suggest that volatilities and exposures to credit risk were already high before the financial crisis, a result driven by look-ahead bias so we were not convinced that this is a useful route to take.

\section{Representing securities and loans}

Our approach views every call report position as a fixed income instrument with conditional return distributions characterized by the duration and risk characteristics of the position. From Section 4.1, we know how to represent the exposure of any instrument to the risk factors we are interested in by simple factor portfolios.

\section{Securities}

The representation of securities positions is straightforward, since we observe fair values for 


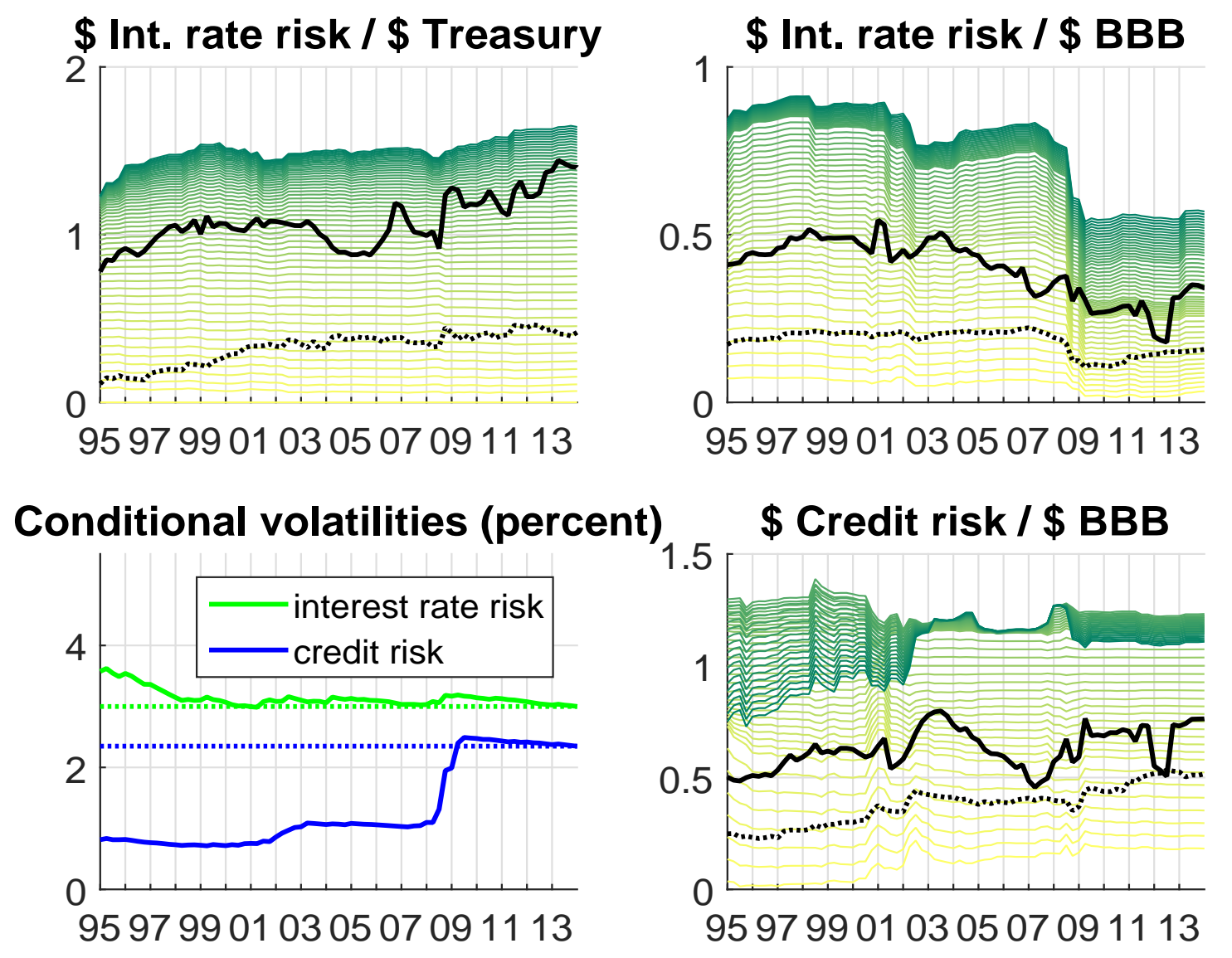

Figure 5: Factor exposures of selected instruments and conditional volatilities of factor returns. Top left panel: interest rate factor exposure of Treasury bonds (dollar value of interest rate factor portfolio with same exposure as one dollar in invested in Tresury bonds). Lines represent different maturities; darker lines correspont to longer maturities. Black solid (dotted) line is average exposure of securities (loan) position of aggregate US banking sector. Top right panel: exposure of $\mathrm{BBB}$ bonds to credit risk. Bottom right panel: exposure of $\mathrm{BBB}$ bonds to credit risk. Bottom left panel: recursively estimated volatility of factors, in percent per quarter. Straight dotted lines indicate full sample volatility estimates.

all securities. To compute the value of the factor portfolios for a position in some instrument, we multiply the fair value of the position with the relevant exposures for that instrument. For broad classes of instruments (such as Treasuries, MBS etc), the resulting factor portfolios then move over time with two forces: changes in the composition of maturity and credit quality, as described in Section 3 and changes in the exposures by instrument illustrated in Section 4.1. ${ }^{20}$

The left column of Figure 6 summarizes exposures of the aggregate banking sector due to securities. The color coding is the same as in the left panel of Figure 3 which provides the "raw

\footnotetext{
${ }^{20}$ For securities held for trading, detailed data on maturities is not available. This item consists of bonds held over short horizons as inventory of market making banks. We proceed under the assumption that the average maturity is similar to that of securities not held for trading.
} 

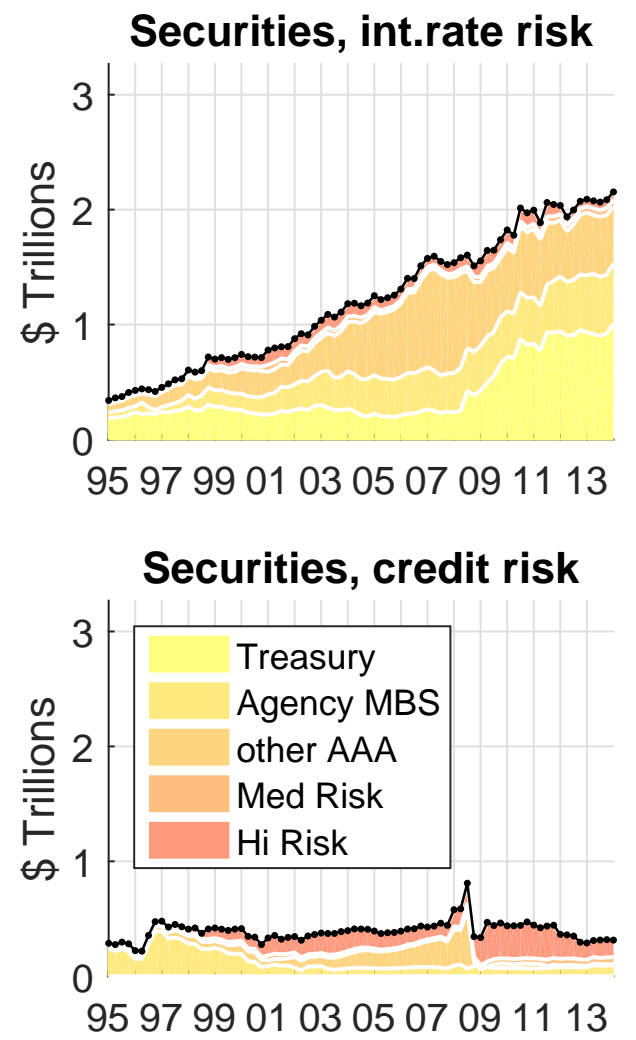

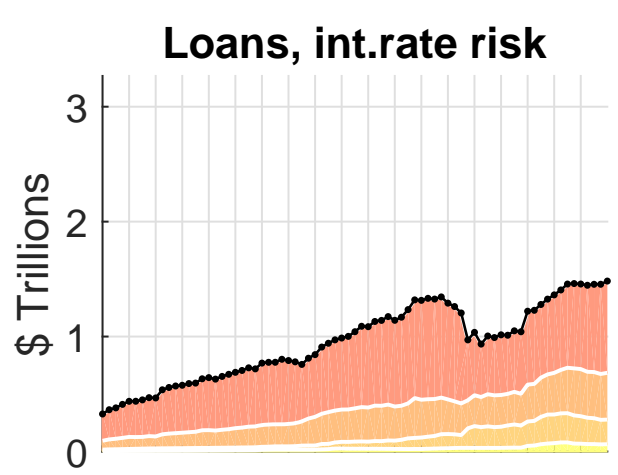

95979901030507091113

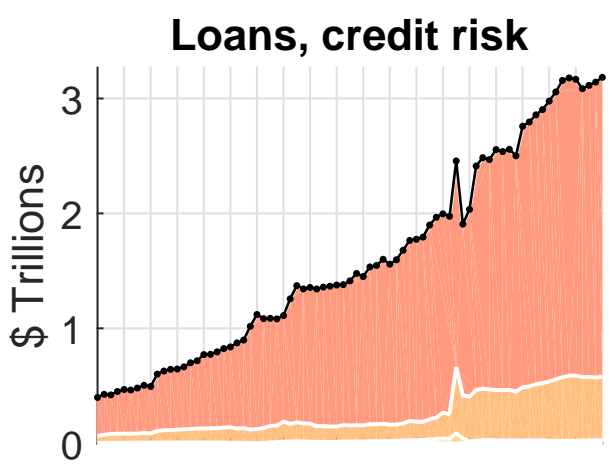

95979901030507091113

Figure 6: Exposures to interest rate risk and credit risk in securities and loan positions for aggregate U.S. banking sector. Colors in all panels reflect risk classes indicated in legend in bottom left.

data" counterpart. The top and bottom panels show exposures to interest rate and credit risk, respectively. As in the analysis of JPMorgan Chase in Section 2, the numbers in the top panels do not add up to the total from Figure 3. A portfolio with the same factor exposure as that held by U.S. banks thus also involves a positive position in cash (or some other instrument that is uncorrelated with our factors).

The results underscore the point that accounting measures are misleading guides to exposure. First, the main source of interest-rate risk is securities, even though securities are only half as large as loans overall. Second, within securities, Treasuries are a key source of interest-rate risk, much more so than mortgage backed securities which load more on credit risk. In particular, the portfolio shift after the financial crisis away from MBS and into Treasuries - a shift that coincided with various quantitative easing measures instituted by the Fed - implied a small decrease in interest-rate risk together with a large increase in interest-rate risk.

\section{Loans}

Most loans are reported in bank balance sheets at face value. Our exposures by instrument cannot be applied directly to face values. Indeed, they translate fair values of instruments into fair 
values of positions in risk factors. Face value is equal to fair value only under special conditions, for example when the loan has no default risk and the yield curve has not shifted since the loan was first issued. More generally, two loans with the same face value could have very different fair values depending on duration, credit risk and the history of interest rates.

To find factor portfolios for loans, we use the fact that loans promise streams of payments and thus look like portfolios of zero coupon bonds. Indeed, consider an installment loan that is amortized according to the standard annuity formula. Given face value, loan rate and maturity, the annuity formula delivers the sequence of equal payments promised by the bond up to maturity. A portfolio of loans of given credit quality is thus equivalent to a portfolio of zero coupon bonds of the same credit quality. We can compute the fair value of each payment using the yield curve for that credit quality. We can then multiply these fair values with the respective exposures of the zero coupon bonds. As a by-product, we obtain an estimate of the fair value of the loan by summing the fair values of all promised payments. ${ }^{21}$

Calculation of fair values at date $t$ requires knowledge of the distribution of maturities, loan rates and credit qualities for each date. We derive this information recursively. Fix a credit quality and suppose we know the distribution of maturities as well as the average (face value weighted) loan rate by maturity at date $t .^{22}$ Consider the transition to date $t+1$. Amortization implies how much face value remains for each maturity $m$ at date $t+1$, call this number $\hat{N}_{t+1}^{m}$. We also observe outstanding loans for each maturity at date $t+1$ in the call reports, say $N_{t+1}^{m} \cdot{ }^{23}$

There are now two cases to consider. First, if $N_{t+1}^{m}>\hat{N}_{t+1}^{m}$, we infer that the difference reflects new issues of loans. We assume that all new loans are issued at the current interest rate for this credit quality. Second, if $N_{t+1}^{m}<\hat{N}_{t+1}^{m}$, we infer that the bank retired more loans and that no new loans were issued. Working through the relevant case for each maturity, we arrive at a new distribution of maturities as well as average face value weighted loan rates by maturity for date $t+1$. To start off the recursion, we assume that at the initial date in our sample all loans are new. The results are not particularly sensitive to initial conditions since many loans are short term and outstanding loans grow exponentially over time.

Our representation of loans is illustrated in the right column of Figure 6 which can be compared to the plot of accounting measures in the right panel of Figure 3. The raw total levels off at around

\footnotetext{
${ }^{21}$ The resulting measure is not necessarily the market price at which the bank could sell the loan. Indeed, banks might hold loans on their portfolios precisely because the presence of transaction costs or asymmetric information make all or parts of the portfolio hard to sell. At least part of the loan portfolio should thus best be viewed as a nontradable "endowment" held by the bank. Nevertheless, our present value calculation will show how the economic value of the endowment moves with interest rates.

${ }^{22}$ As for loans, the call reports provide maturity buckets for different types of securities. We again proceed under the assumption that the maturity is uniform conditional on the bucket and that the maximal maturity is 20 years.

${ }^{23}$ At this point information on mergers is important. If the bank acquired another bank so that the first call report after the merger is dated $t+1$, we form $\hat{N}_{t+1}^{m}$ by adding amortized loans of acquirer and target.
} 
$\$ 6$ trillion in late 2007. Our exposure measures show that credit risk in fact increased by $\$ 1$ trillion since then. At the same time, exposure to interest-rate risk temporarily declined after the financial crisis: this is due to the breakdown of correlation between risky and riskless bond prices that began in late 2008. We also note that our approach finds a spike in credit risk right before the financial crisis worsens in the fall of 2008 - this spike is visible both for loans and securities. Overall, however, most of the exposure to credit risk on banks' books comes from the loan portfolio.

\section{Liabilities}

We treat short term liabilities as short term bonds. For long term debt, we follow a similar procedure for constructing vintages of coupon rates as for loans and then value the resulting payment streams. The difference between bonds and loans is that long term debt is treated as coupon bonds issued at a par value equal to the face value. As a result, the payment stream consists of a sequence of coupon payments together with a principal payment at maturity, and the face value is not amortized.

\section{Representation of interest rate derivatives}

For interest-rate derivatives, we estimate exposures from data on fair and notional values. We treat all interest-rate derivatives as swaps. ${ }^{24}$ There are two basic inference problems. First, many banks deal in swaps. As a result, their total notionals reflect in part large offsetting positions that imply only small exposures to our risk factors. For example, if a bank offsets each pay-fixed swap with one client by a pay-floating swap with another client then it is exposed to interest-rate risk only through the present value of bid-ask spreads. Second, we do not know the direction of trades banks make on their own account.

The following notation is helpful. Consider an individual swap position described by a triple $(\phi, m, s)$, where $\phi$ is the direction $(\phi=1$ for pay-fixed and $\phi=-1$ for pay-floating), $m$ is the maturity and $s$ is the locked in swap rate. As in (2), we denote the fair value per dollar notional of pay-fixed swap by $F_{t}(s, m)$. The net fair value of the individual position at date $t$ per dollar notional is given by $\phi F_{t}(s, m)$. Gross fair values record the absolute value of all positive and negative positions. Per dollar of notional value, the contribution of an individual position to gross fair value is thus given by $\left|F_{t}(s, m)\right|$.

We now describe the estimation approach in two steps. We show first that - since $F_{t}$ is linear in $s$ - it is possible to decompose a bank's total swap book into $(i)$ the present value of rents from market making and $(i i)$ gains from trading on own account. Part $(i)$ can be estimated from data

\footnotetext{
${ }^{24}$ Futures and forwards relate linearly to swap rates as is the case for swaps (which can be viewed as bundles of forwards). We ignore nonlinearities due to options which however matter only for a small share of notionals.
} 
on notionals and bid ask spreads only. The second step is then to estimate part ( $i i$ ) from data on gross and net fair values as well as interest rate history.

Here we infer the direction of trade $\phi$ from a comparison of net fair values (that is, cumulative gains) and interest rate history. Intuitively, if the bank has made positive gains $(\phi F>0)$ after interest rates have recently fallen (so that $F<0$ ), then it is likely that the bank has entered pay-floating swaps $(\phi<0)$.

\subsection{Step 1: rents from market making}

In a textbook frictionless market, swap rates are determined at the inception date (when the swap contract is written) so as to set the initial fair value equal to zero. In practice, swap dealers make money by adjusting initial swap rates to incorporate spreads. In particular, the swap rate on a pay-fixed (pay-floating) swap is typically lower (higher) than the rate that makes the fair value zero. While bid-ask spreads in the swap market are small - they average 2 basis points over our sample - they can matter for fair values since they multiply large notionals.

We assume that the initial rate on any swap of direction $\phi$ and maturity $m$ takes the form $s=\bar{s}-\phi z$, where $\bar{s}$ satisfies $F_{t}(\bar{s}, m)=0$ and $z$ is one half the bid-ask spread. Following standard terminology, we refer to $\bar{s}$ as the "mid-market rate"; it is half way between the bid and ask rates. Swaps started at date $t$ thus have positive fair value only if there is a positive bid-ask spread. In contrast, "vintage" positions that were started before date $t$ can contribute to fair value also because the mid-market rate has changed since the inception date. Indeed, for any individual vintage position with remaining maturity $m$ at date $t$, the locked in swap rate $s$ reflects some past mid-market rate $\bar{s}$ for which we may have $F_{t}(\bar{s}, m) \neq 0$.

The bank's swap book contains many positions. For each direction $\phi$ and maturity $m$, let $\hat{N}_{t}^{\phi, m}$ denote vintage notionals for that direction and maturity that are outstanding at date $t$, and let $\bar{s}_{t}^{\phi . m}$ denote the average mid-market rate, weighted by notionals, on those positions. Similarly, for date $t$ and maturity $m$, let $N_{t}^{\phi, m}$ denote all notionals with that direction and maturity (including those entered at date $t$ ), and let $z_{t}^{m}$ denote the average bid-ask spread, weighted by notionals, on those positions. The distinction between vintage and total notionals is important here because only the former contribute to fair value due to changes in interest rates.

We can now decompose the total net fair value of the bank's swap book. Summing over all 
individual positions $(\phi, m, s)$, we obtain

$$
F V_{t}=\underbrace{\sum_{m} N_{t}^{m} z_{t}^{m} \sum_{j=1}^{m} P_{t}^{(j)}}_{F V_{t}^{\text {rent }}}+\underbrace{\sum_{\phi, m} \hat{N}_{t}^{\phi, m} \phi F_{t}\left(\bar{s}_{t}^{\phi, m}, m\right)}_{F V_{t}^{\text {own }}} .
$$

The first term $F V_{t}^{r e n t}$ consists of the present value of bid-ask spreads. It scales with total notionals and is independent of locked-in mid-market rates. The second term $F V_{t}^{\text {own }}$ is zero for a pure intermediary who does not trade on its own account. ${ }^{25}$ If instead the bank does some trading on its own account, then $F V_{t}^{\text {own }}$ records cumulative net gains due to changes in mid-market rates, quantitatively the major source of net gains. We thus label $F V_{t}^{\text {own }}$ the fair value due to trading on own account.

\section{Measurement}

We obtain information on bid-ask spreads in the swap market by maturity from Bloomberg. Bid-ask spreads for contracts between dealers tend to be lower than those in contracts between dealers and clients. To assess the share of contracts a bank does with other dealers, we use data on net credit exposure in derivatives to various counterparties, available in the call reports since 2009. Finally, we also have data on the maturity of notionals in three broad maturity buckets: less than one year, 1-5 years and more than 5 years, as shown in Figure 4.

For every maturity $m$, the spread factor $z_{t}^{m}$ in (3) reflects (one half) the average bid-ask spread for all the swaps currently on the bank's books. To the extent that bid-ask spreads change over time, its magnitude depends on how many current swaps were initiated in the past when bid-ask spreads were, say, higher. To capture this effect, we construct a vintage distribution of swap notionals analogously to the vintage distributions of loans and long-term debt discussed above. We use data on bid-ask spreads on new swaps to find, for each maturity and period, the total bid-ask spread payment earned by swaps of that maturity in that period.

More specifically, suppose we know the distribution $\left\{N_{t}^{m}\right\}$ of total notional values by maturity $m$ as well as the distribution of bid-ask spreads on new swaps by maturity, that is, the sequence $\left\{2 z_{t}^{m}\right\}$. We assume that in the first sample period, all swaps are new, and we record the stream of bid-ask spread payments $\left\{z_{0}^{m}\right\}$ on those swaps. We then proceed recursively: for each period and maturity, new swaps are defined as the difference between total notionals for that period and "old" notionals that remain from the previous period, taking into account that the old swaps have

\footnotetext{
${ }^{25} \mathrm{~A}$ pure intermediary enters only exactly offsetting pay fixed and pay floating positions, that is, $\hat{w}_{t}^{1, m}=\hat{w}_{t}^{-1, m}$ and $\bar{s}_{t}^{1, m}=\bar{s}_{t}^{-1, m}$ for all $m$. Importantly, even a pure intermediary can have positive fair value because $F V^{\text {rent }}>0$. For example, the combined fair value from a pair of exactly offsetting pay-fixed and pay-floating positions with notionals $N / 2$ each at rates $\bar{s}-z$ and $s+z$ is $z N \sum_{j=1}^{m} P_{t}^{(j)}$.
} 
aged by one period. We then use the current bid-ask spreads to add to the stream of payments for all future periods.

\subsection{Step 2: net gains from trading on own account}

To analyze banks' trading on own account, that is, the second term in (3), we make two simplifying assumptions on bank trading strategies. First, the maturity distributions of notionals as well as the locked in average mid-market rates do not depend on the direction $\phi$. Formally, we have $\bar{s}_{t}^{1, m}=\bar{s}_{t}^{-1, m}$ for all $m$ and there exist weights $\hat{w}_{t}^{m}$ such that $\hat{N}_{t}^{\phi, m}=\hat{w}_{t}^{m} \hat{N}_{t}^{\phi}$ where $\hat{N}_{t}^{\phi}$ are total notionals on vintage positions of direction $\phi$. This assumption is trivially satisfied if the bank is a pure intermediary, as well as when it only trades on its own account in one direction. More generally, it requires that gains on the typical trade on own account are similar to those on the typical intermediated trade.

The assumption implies that we can write $F V_{t}^{\text {own }}$ as net notionals invested in pay fixed swaps, $\hat{N}_{t}^{1}-\hat{N}_{t}^{-1}$, multiplied by the average net gain on pay fixed swaps, which also equals the average net loss on pay floating swaps:

$$
F V_{t}^{\text {own }} \approx\left(\hat{N}_{t}^{1}-\hat{N}_{t}^{-1}\right) \sum_{m} \hat{w}_{t}^{m} F_{t}\left(\bar{s}_{t}^{m}, m\right)
$$

where $\bar{s}_{t}^{m}$ is the average locked mid-market rate for maturity $m$. Our second assumption is that this average gain can be approximated by the net gain at the average maturity $\bar{m}_{t}=\sum \hat{w}_{t}^{m} m$. It is trivially satisfied if all trades take place at the same maturity. More generally, it requires that maturities and swap rates are not too different across individual positions.

Applying both assumptions, we represent $F V_{t}^{\text {own }}$ as

$$
F V_{t}^{\text {own }} \approx\left(\hat{N}_{t}^{1}-\hat{N}_{t}^{-1}\right) F_{t}\left(\bar{s}_{t}, \bar{m}_{t}\right)
$$

The bank's net fair value from trading on own account is positive if it has more pay fixed (pay floating) swaps and the current swap rate at the average maturity $\bar{m}_{t}$ is lower (higher) than the locked in rate $\bar{s}_{t}$. The size of the gain or loss is given by the difference between the current and locked in swap rates. Under our assumptions, we can thus view the bank's trading on its own account as choosing which way to bet on the level of the swap yield curve. Fair values can be negative if the yield curve moves against the bank, that is, if it has more pay-fixed (pay-floating) swaps and the current swap rate is lower (higher) than the locked-in rate.

Our assumptions are motivated by the fact that most movements in interest rates are due to shifts in the level of the yield curve. Suppose banks have entered many positions of similar 
maturities at past dates that are relatively close together, some pay fixed and some pay floating (perhaps partly offsetting due to intermediation). A downward shift in the level of the yield curve will then simultaneously generate losses on all pay-fixed positions and gains on all pay-floating positions. The first order effect on gains and losses can be written in terms of the gain and loss at the average maturity. Since a level factor accounts for about $90 \%$ of the variation in yields at the quarterly frequency we study, this is the type of movement we are interested in.

Our assumptions also imply that we can estimate the amount of (unobservable) net notionals in pay fixed swaps $\hat{N}_{t}^{1}-\hat{N}_{t}^{-1}$ from total notionals together with net and gross fair values. Indeed, the appendix shows that if bid-ask spreads are sufficiently small, then our assumptions imply that gross fair value can be written as

$$
G V_{t} \approx \hat{N}_{t} F_{t}\left(\bar{s}_{t}, \bar{m}_{t}\right)
$$

In other words, the ratio of net to gross vintage notionals is approximately the same as the ratio of net to gross fair values.

\section{Estimation}

As an observable from which to infer the bank's trading strategy, we form the fair value per dollar of net notional used by the bank to trade on its own account

$$
\mu_{t}:=\operatorname{sign}\left(F V_{t}-F V_{t}^{r e n t}\right) \frac{G V_{t}}{N_{t-1}} \approx \phi_{t} F_{t}\left(\bar{s}_{t}, \bar{m}_{t}\right) \text {. }
$$

To calculate the multiple $\mu_{t}$ for quarter $t$, we use $F V_{t}$ and $G V_{t}$ from the end of quarter call reports. We identify vintage notionals $\hat{N}_{t}$ with all notionals $N_{t-1}$ outstanding at the end of the previous quarter $t-1$. The bond prices that enter the valuation factor $F_{t}$ are taken from the swap curve.

Our observation equation is

$$
\mu_{t}=\phi_{t} F\left(\bar{m}_{t}, \bar{s}_{t}\right)+\varepsilon_{t},
$$

where the average swap rate $\bar{s}_{t}$ and the direction of trading $\phi_{t}$ are unknown and where the measure-

ment error is iid normal with mean zero and variance $\sigma_{\varepsilon}^{2}$. We set the variance of the measurement error $\sigma_{\varepsilon}^{2}$ to $10 \%$ of the variance of the multiple $\mu_{t}$.

We take a Bayesian approach to estimation starting from a prior over the joint sequence of directions and average locked-in swap rates $\left(\phi_{t}, \bar{s}_{t}\right)$. Our choice of prior for the swap rate is motivated by two considerations. First, locked-in swap rates must have been realized recently. It makes no sense, for example, to expect that near-zero interest rates that prevailed in 2011 could have been locked in in 2007. Second, it is plausible that banks' direction of trading $\phi_{t}$ exhibits some persistence - banks do not erratically change their view of the level of the yield curve from one quarter to the next. 
The prior over the direction $\phi_{t}$ is a symmetric two state Markov chain with a $10 \%$ probability of switching the sign of $\phi_{t}$. The prior over the swap rate $\bar{s}_{t}$ for the date $t$ estimation is given by the empirical distribution of swap rates over the last five years. To implement the estimation, we discretize the swap rate on a fine grid. All updating is therefore done with discrete distributions and posteriors are available in closed form. We obtain posteriors over sequences of $\mu_{t}, \phi_{t}$ and $\bar{s}_{t}$ for each of the banks in our sample.

\section{Estimation results}

To illustrate how the estimation works, Figure 7 shows the trading positions for JPMorgan Chase. The top left panel shows the evolution of total notional values. These numbers are large because of the lack of netting of interdealer positions in the call reports: the notionals of each bank by itself amounts to several times U.S. GDP. The blue line in the top right panel shows the

multiple $\mu_{t}$, that is the net fair value as a share of net notionals used for trading on the bank's own account.

The bottom panels display the estimation results. The bottom left panel is the posterior probability of a pay-fixed position $\left(\phi_{t}=1\right)$. In the bottom right panel, the blue line shows the swap rate at the average maturity $\bar{m}_{t}$. The red and green solid lines represent the conditional posterior median swap rates given that the direction is pay fixed or pay floating, respectively. The dotted red and green lines show the posterior conditional interdecile range for the swap rate. The red line labeled "estimate" in the top right picture represents an estimate of the multiple obtained by evaluating $\phi_{t} F\left(\bar{s}_{t}, \bar{m}_{t}\right)$ from (7) based on the direction with the higher posterior probability and the median swap rate conditional on that direction.

The estimation infers pay-fixed positions during times of temporarily rising interest rates. For example, during 2005-07, the fair value is positive and it is not plausible to find recent high enough interest rates to justify it. The code thus infers that a low rate had been locked in as part of a pay-fixed strategy. In contrast, the spectacular gains enjoyed by JPMorgan Chase in both the 2001 recession and the Great recession when interest rates fell strongly suggest a pay-floating strategy.

We have conducted sensitivity analysis in two directions. First, we have varied the variance of measurement error variance $\sigma_{\varepsilon}^{2}$ and the prior on the Markov chain for trading direction. Both smaller prior variance $\sigma_{\varepsilon}^{2}$ and a smaller prior probability of keeping the current direction $\phi_{t}$ generate a more volatile posterior probability of pay-fixed swaps; in particular the posterior responds more to sudden spikes in interest rates. Intuitively, if the estimation tries to explain more of the wiggles in the multiple $\mu_{t}$ with changes in bank strategy (as opposed to measurement error) and is not constrained by path dependence of positions, then it infers more frequent changes in direction. The overall pattern of strong evidence for pay fixed positions is not affected, however - identification of this pattern does not come from high frequency movements but rather from the fact that banks 
gain a lot in recessions when interest rates fall.

Second, we have experimented with a more complicated prior that expresses our judgement that bank positions are path dependent in a different way. In particular, one might expect that $(i)$ the average locked in swap rate should be relatively closer to the current swap rate if notionals have been growing quickly recently, because new notionals always reflect current rates and $(i i)$ a rate that was quoted at some date $\tau<t$, and therefore could be locked as of date $t$, should carry little weight if there are intermediate dates in the interval $(\tau, t)$ such that that rate looks very implausible. One way to code these considerations into a prior is to formulate a stylized trading strategy that recursively updates the locked-in swap rate in response to changes in notionals. Results with this prior again confirmed the pattern of pay-fixed positions. To maximize transparency of the results, we report here only results with the simple prior based on a Markov chain.

\section{$7 \quad$ Risk exposure over time}

In this section we show how overall risk taking by the U.S. banking sector has changed over the last 20 years. We use our factor portfolio approach to compare exposures both across banks and across positions. In particular, we are interested in risk choices of banks of different size as well as business models, distinguishing banks with a large market making division from more traditional banks. Moreover, we investigate the role of interest-rate derivatives in potentially hedging the risk inherent in other bank business.

\section{Exposures and market concentration}

An overview of total bank risk taking is provided in Figure 8. The top row shows positions in the interest rate and credit risk factor portfolios in the left and right panels, respectively. In both panels, totals reflect the aggregate U.S. baking sector, while the top 4 banks are shaded more lightly. Overall, the dollar value of both interest risk and credit risk factor portfolios increased steadily with the size of banking. In addition, interest-rate risk exposures increased quickly in both recessions whereas credit risk spiked right before the financial crisis.

A breakdown by size shows the increasing concentration in U.S. banking. Much of the growth of the overall banking sector over our sample went along with a steady increase in the share of the top 4 banks - JPMorgan Chase, Citi, Wells Fargo and Bank of America. ${ }^{26}$ Some of the spikes in those banks' exposures during the financial crisis can be traced to merger activity for example, JPMorgan Chase took over the remains of Bear Stearns in mid 2008 and Bank of

\footnotetext{
${ }^{26}$ Those four banks are the largest BHCs in terms of total assets today as well as for most of our sample. Their share of total assets jumped above one third in the late 1990s through merger activity and gradually increased thereafter; it was $57 \%$ at the end of 2013 .
} 

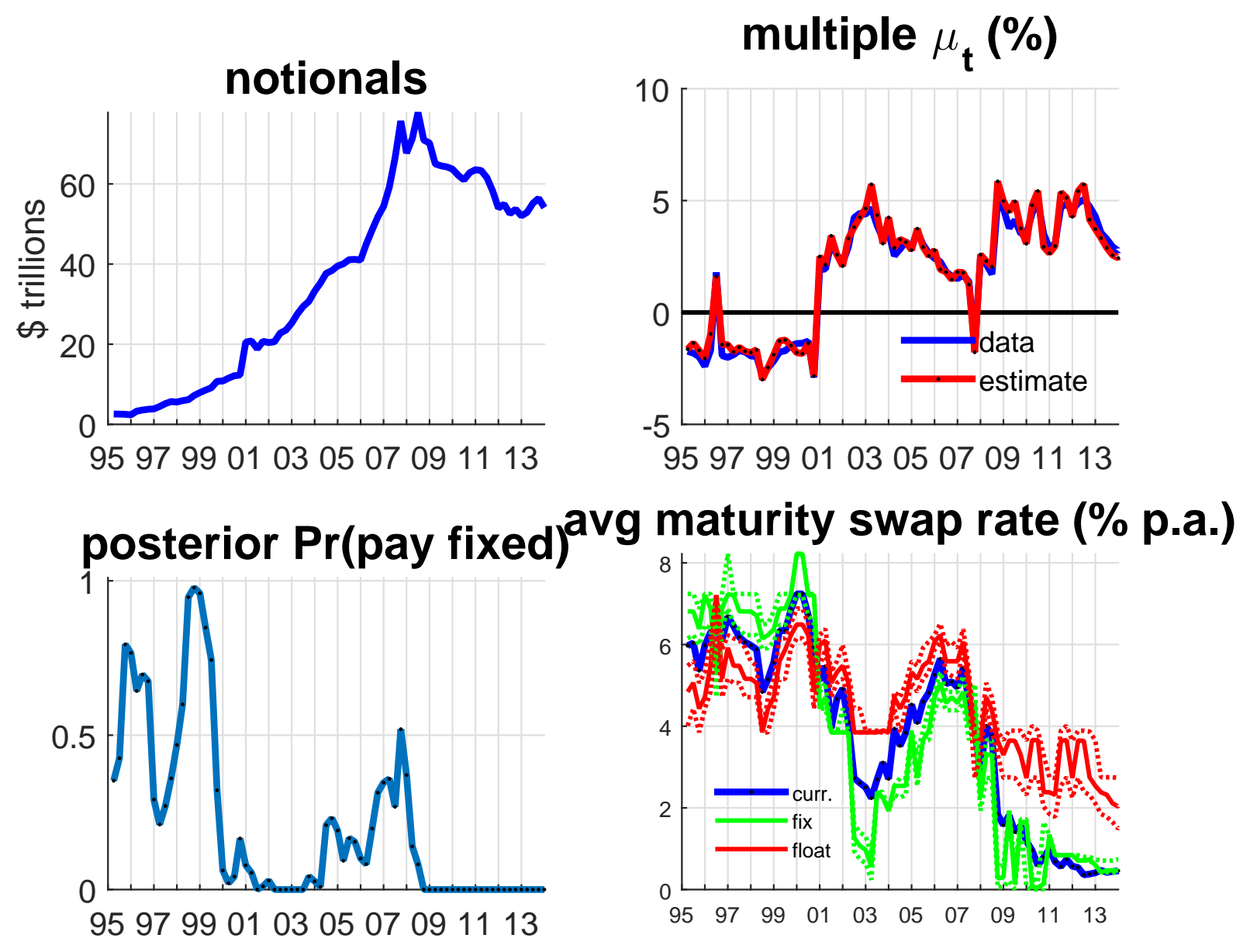

Figure 7: Trading positions for JPMorgan Chase. Top left in blue are total gross notionals. Top right in blue is the observed multiple $\mu_{t}$ and in red is the estimated multiple $\phi_{t} F\left(\bar{s}_{t}, \bar{m}_{t}\right)$ based on the direction with higher posterior probability and the median swap rate conditional on that direction. Bottom left is the posterior probability that the direction is pay fixed. Bottom right in blue is the conditional posterior median swap rate that was locked in. The red and green solid lines represent the conditional posterior median swap rates given that the direction is pay fixed or pay floating. The dotted lines represent conditional posterior interdecile ranges for the swap rate.

America acquired Merrill Lynch at the end of 2008. Both investment banks had large trading portfolios that temporarily increased the interest-rate risk exposure of their new parent banks.

Interestingly, both boom-boom episodes in our sample - namely the late 1990s stock market boom and the mid 2000s housing boom - see a marked increase in the share of exposures born by the top four banks. For example, the share of the total interest-rate factor portfolio held by the top four banks increased from around 20\% in 1997 to about 60\% in 2001, and it also increased from about $50 \%$ in 2004 to more than $80 \%$ in early 2009 . At the same time, the share of the total credit-risk factor portfolio increased from $20 \%$ in 1997 to about 35\% in 2001 as well as from $35 \%$ in 2004 to $55 \%$ in early 2009 . 


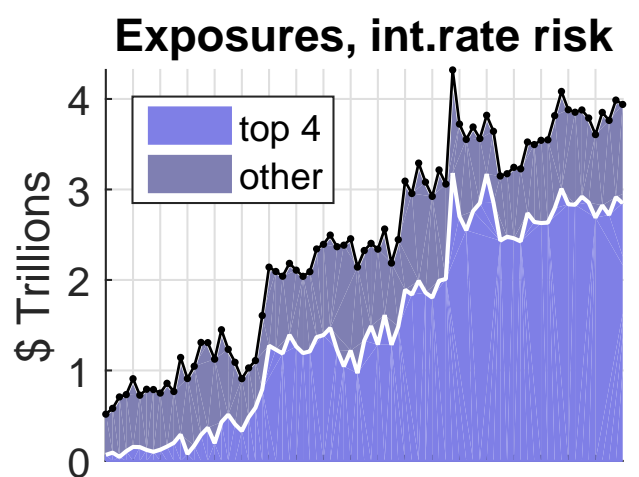

95979901030507091113

\section{Typical gain/loss, int.rate risk}

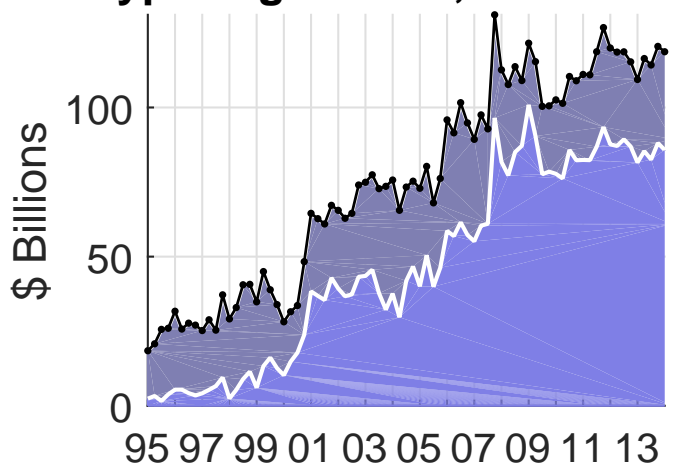

Exposures, credit risk

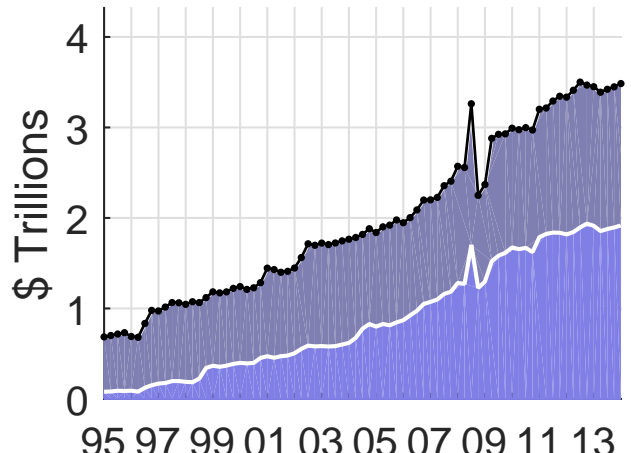

Typical gain/loss, credit risk

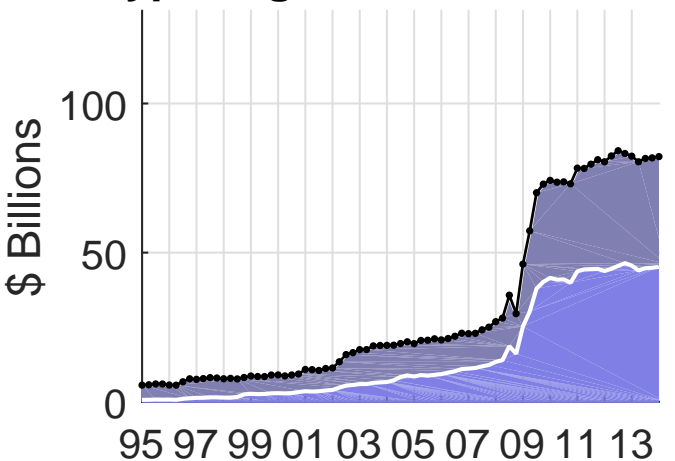

Figure 8: Top row: exposures to interest rate risk (left panel) and credit risk (right panel). Black lines are total factor exposures of U.S. banking sector; shading indicates contribution of top 4 bank holding companies (light) and all other banks (dark). Bottom row: gains or losses from one standard deviation realization of interest rate factor (left panel) and credit risk factor (right panel). Black lines are total gains / losses of US banking sector; shading indicates share of top 4 (light) and all others (dark).

\section{Typical gains and losses}

The bottom row of Figure 8 computes gains or losses from a one standard deviation innovation in factor returns. It thus provides an alternative way to assess risk: it effectively multiplies the portfolio numbers from the first row with the conditional volatilities for the two risk factors shown in the bottom left panel of Figure 5. This explains the similarities and differences across panels: since the volatility of interest-rate risk is close to constant, the top and bottom left panels looks qualitatively very similar. In contrast, the bottom right panel shows a substantial increase in the typical credit-risk gain or loss in the wake of the financial crisis. 


\subsection{Market makers versus traditional banks}

A key feature of recent U.S. banking regulation was the gradual dismantling of the Glass-Steagall act which separated investment and commercial banking. Our sample is interesting in part because it contains the November 1999 enactment of the Gramm-Leach-Bliley act, the formal repeal of Glass-Stegall. The opening of new opportunities was followed by several mergers between investment and commercial banks that generated large banks that are also active market makers, not least the union of Chase Manhattan and JP Morgan.

Figure 9 compares risk taking over time for banks with different business models. The right column isolates the holdings of "market makers", here defined as banks that have more of $10 \%$ of assets designated "trading assets". In the left column we show the remaining banks, labeled "traditional". In both columns the top panel plots the position in the interest-rate factor while the bottom panel shows the credit-risk factor. In all panels, we distinguish risk incurred because

of trading (trading assets minus trading liabilities, but excluding interest-rate derivatives), as well as risk due to interest-rate derivatives held for trading.

The differences between the two groups of banks is striking. Up until the financial crisis, traditional banks only very gradually increased both interest rate and credit risk. By construction, traditional banks have very little trading assets as a share of total business, so all movements in risk are due to non-trading business. The crisis left them with a larger share of low quality loans, which resulted in more credit risk. At the same time, the increase in volatility of long term bonds contributed also to an increase in interest-rate risk. Overall, then traditional banks showed only a modest buildup of risk pre-crisis - the main increase occurred after 2008.

In contrast, market makers strongly increased risk taking via trading assets and derivatives essentially right after the passage of Gramm-Leach-Bliley. The exposure to interest-rate risk from traditional business for market makers was in fact slightly negative around the turn of the millennium. During the boom of the 2000s, both traditional and non-derivatives trading contributed to a build up of interest-rate risk. When this source of risk taking declined in early 2007, exposures due to derivatives helped overall interest-rate exposure to remain high. At the same time, credit risk increased, in a small part also through trading business, towards a peak in 2008. In the aftermath of the crisis, the risk exposure of market maker banks was actually smaller than at the peak of the boom.

\subsection{The role of interest rate derivatives}

Textbook treatment of interest-rate derivatives often emphasizes the potential for banks to hedge exposure due to other business. An increase in the level of the yield curve also lowers long interest 


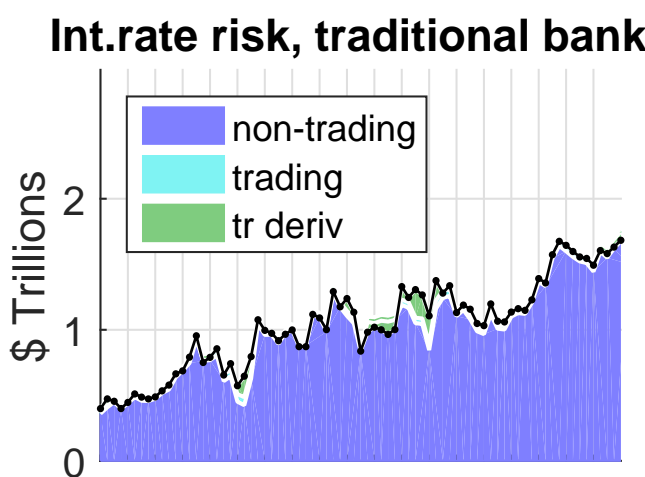

95979901030507091113

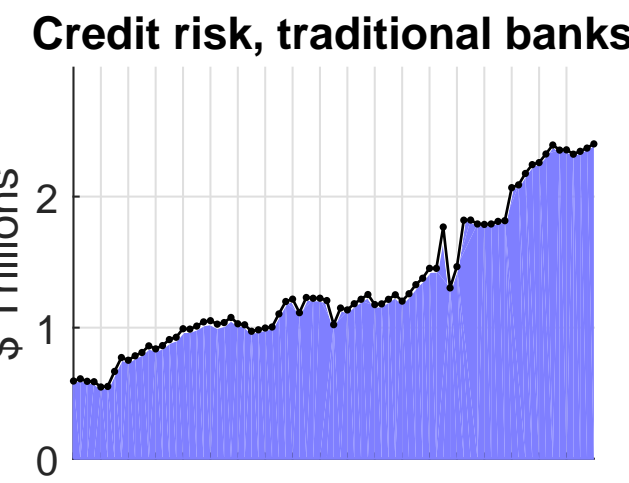

95979901030507091113

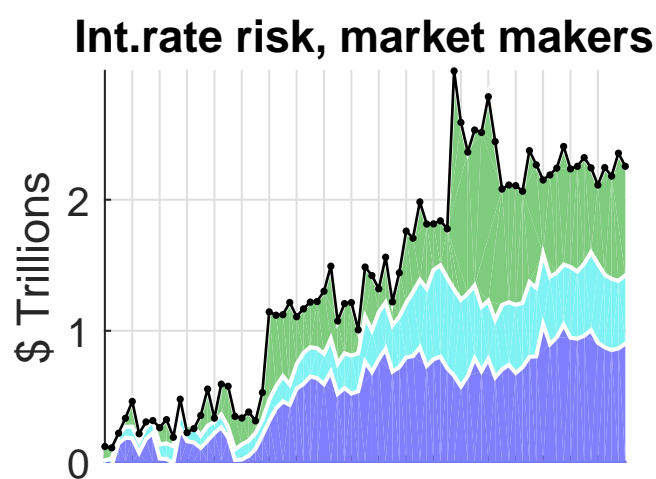

95979901030507091113

\section{Credit risk, market makers}

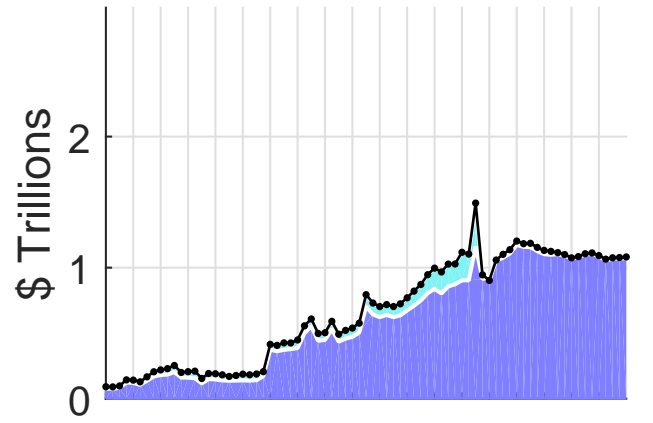

95979901030507091113

Figure 9: Factor exposures of market makers (share of trading assets $>10 \%$; right column) and traditional banks (all others; left column). Top panels: interest-rate risk; black line is total exposure; shaded areas indicate contributions of derivatives held for trading (green), other trading assets or liabilities (light blue) and other business (purple). Bottom panels: credit risk.

rates relative to short rates. Banks that lend long and borrow short thus earn smaller term spreads; moreover, the value of their long term assets declines. In contrast, a decline in the level typically goes along with a steepening of the yield curve which benefits banks. One might therefore expect that banks choose derivative positions that pay off a lot when interest rates rise, such as pay-fixed swaps.

Our calculations show that most banks do not use interest-rate derivatives for hedging. Figure 10 breaks down interest-rate risk exposures for both traditional banks and market makers - already shown in the first row of Figure 9 into derivatives and non-derivatives components. For market makers (in the right panel), we further distinguish derivatives held for trading from those held not for trading. For traditional banks the former position is negligible. In contrast, for market makers derivatives held for trading is the bulk of the derivatives positions, as already seen in Figure 9.

In Figure 10, the total interest-rate risk exposure is plotted again as a solid black line. The area shaded in green represents the contribution to the total of exposure due to derivatives. It can be positive or negative and is accordingly drawn below or above the black line representing total 


\section{Traditional banks}

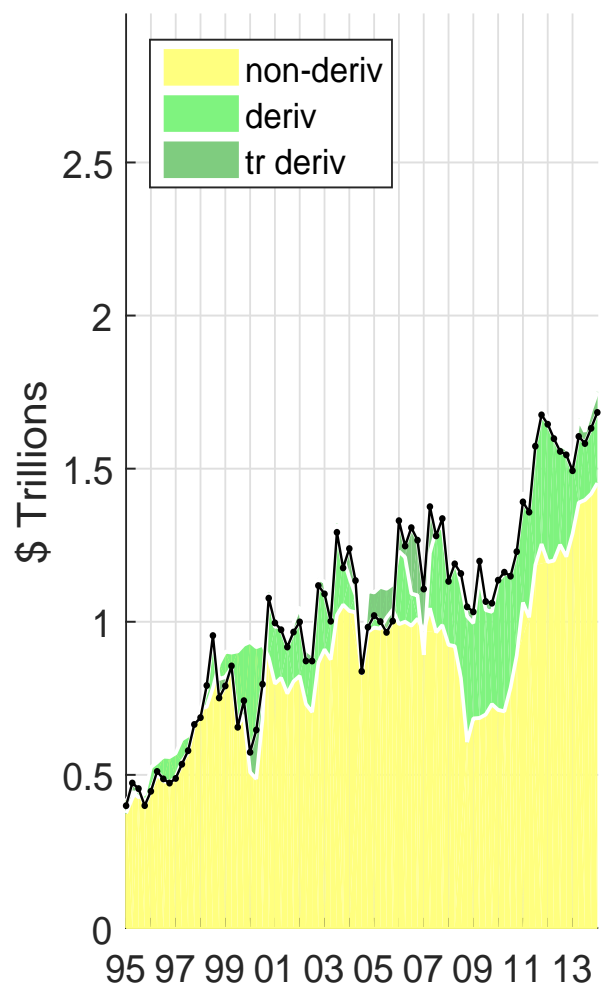

Market makers

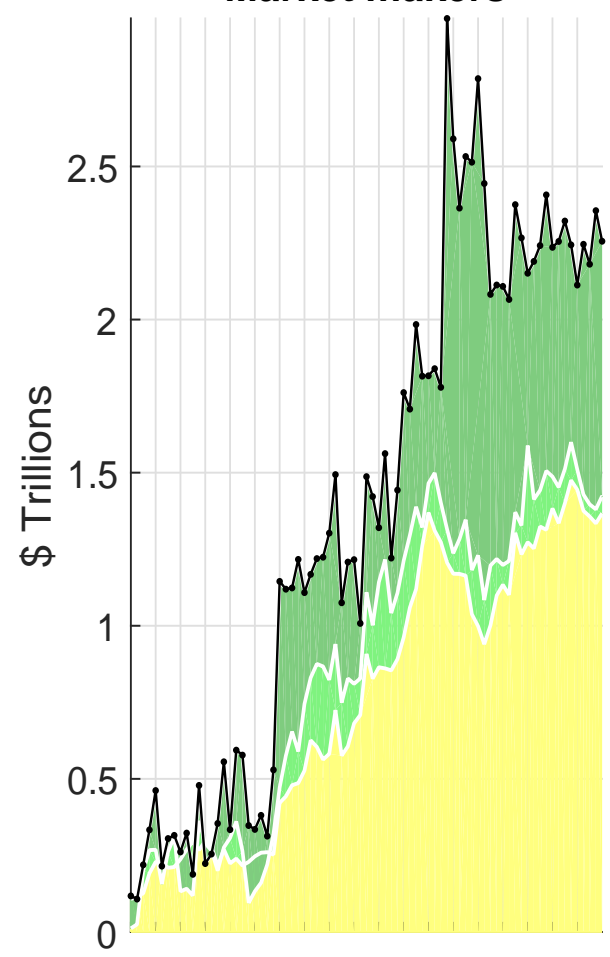

95979901030507091113

Figure 10: Interest rate exposures of market makers (share of trading assets $>10 \%$; right panel) and traditional banks (all others; left panel). Black solid line represent total interest-rate exposures. Shaded areas indicate contributions of derivatives held for trading (dark green), derivatives held not for trading (light green) and other business net of hedging via derivatives (yellow).

exposure. For most of the sample, the contribution of derivatives is positive and the black line serves as an upper margin of the colored area; the yellow area then represents the total exposure due to non-derivatives business. However, there are episodes in the late 1990s where the overall exposure of traditional banks due to derivatives is negative, so that the green area lies above the black line; the yellow area is non-derivatives exposure net of hedging by derivatives, which is now positive.

While the average traditional bank exhibits some episodes of hedging in the 1990s, interestrate risk is built up in the 2000s in part by entering pay floating swap positions. Gains on these positions, especially as interest rates begin to fall during the financial crisis, leave traditional banks with a substantial increase in interest-rate risk. The behavior of market makers' exposures through derivatives throughout the 2000s is broadly similar. The one notable difference is that market makers' exposures remained large even after the crisis as traditional banks' exposures declined again. The main point, however, is that banks incurred similar exposures through derivatives and other business: for both types of positions, increases in interest rates are bad. 


\subsection{The cross section of risk exposures}

So far we have only compared banks by broad size class or business model. Since our approach summarizes exposures by two numbers for any given date, it lends itself to graphical representation of the cross section of factor exposures. Figure 11 compares those cross sections for the first quarter of 2009 (top row) and the first quarter of 2013 (bottom row). It illustrates the heterogeneity in banks' risk strategy as well as how those strategies changed during the recovery from the financial crisis.

The left column of the figure plots, for each bank, factor exposures relative to assets. The portfolio positions in the interest-rate and credit-risk factors is shown along the horizontal and vertical axes, respectively. Each dot represents a bank that filed a call report in the relevant quarter: we have 848 banks in 2009 and 893 banks in 2013. The size of the dots increases with bank size - the top 4 banks are labeled explicitly as JPM (JPMorgan Chase), BofA (Bank of America), Citi (Citigroup) and WF (Wells Fargo \& Co). The color of the dots indicates the share of trading assets in total assets: light blue is a share of zero and the share increases from blue to pink.

\section{Heterogeneity in factor exposures}

There is a lot of heterogeneity in risk taking among U.S. banks. Credit risk exposures are all positive but range widely between $10 \%$ and $50 \%$ of total assets. Interest-rate exposures are negative for a small share of banks - some banks actually gain when the level of the yield curve shifts up - but mostly range between zero and $50 \%$ of assets. The correlation between the two exposures is positive throughout our sample - it was .29 in Q1 2009 and .70 in Q1 2013. In other words, that takes more credit risk relative to assets also has a larger exposure to interest-rate risk. This feature is apparent both for the large cloud of small banks who do almost no trading - the small light blue dots - and for the purple or pink market makers who are typically larger and also include the top 4.

Comparison of the top and bottom panels shows that the cross section dispersion of both types of exposures increased markedly in recent years. Right after the financial crisis, credit risk appeared still relatively concentrated, especially for the small banks. In the 2013 panel, the cloud of small light blue dots has dispersed more and shifted to the right. Moreover, market maker banks including the top 4 no longer appear pushed towards the bottom right in the figure, with relatively more interest-rate risk due to their securities holdings. Instead, in recent years the relative risk exposures of market makers and traditional banks appear to have become more similar.

\section{Hedging interest rate risk with derivatives}

While we have seen that the average bank does not use derivatives to hedge other business, 

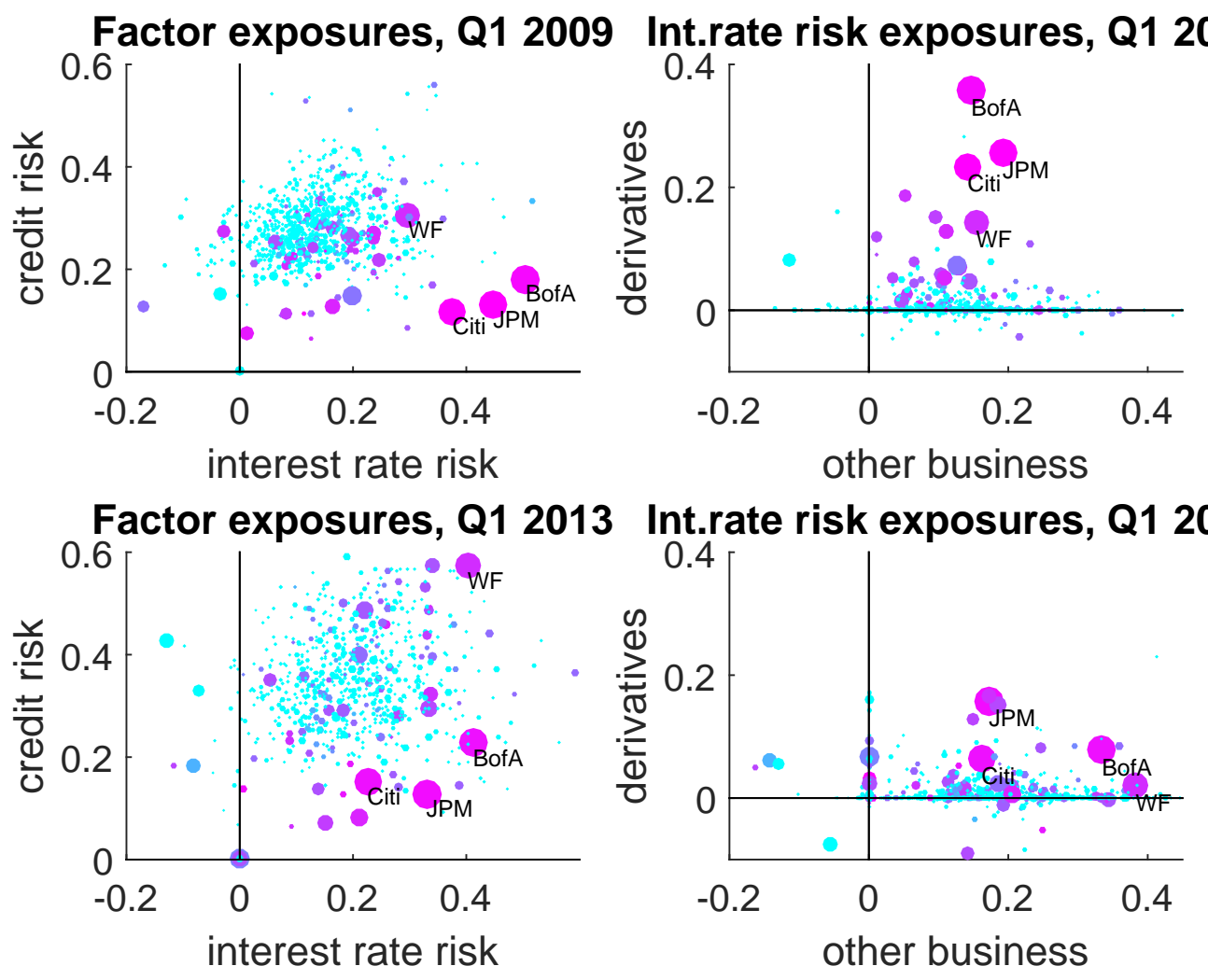

Figure 11: Cross section of exposures. Left column: total bank interest rate and credit risk factor exposures Q1 2009 (top) and Q1 2013 (bottom). Right column: bank interest rate exposures via derivatives and other business. Dots represent value of factor portfolios relative to total assets for all banks in data at sample date. Size increases with total assets. Color indicates share of trading assets in total assets from zero (light blue) to over 10\% (bright pink).

this is not the case for all banks. The right row of Figure 11 compares interest-rate risk exposures, again stated relative to assets, that are due to derivatives (measured along the vertical axis) and other business (measured along the horizontal axis). While the plots contain the same number of dots as those in the left column, fewer are visible since many banks with zero derivatives cluster on the horizontal axis: the share of banks with nonzero derivatives books was only $48 \%$ in 2009 and $52 \%$ in 2013.

In both years, most banks, and in particular large banks with important trading business, had positive exposures from both derivatives and other business. What changed is that in 2013 exposure due to traditional business became relatively more important than that from derivatives. At the same time, there is again a lot of heterogeneity. For small banks, exposure due to derivatives tends to be small relative to that from other business, and it is actually negative for some banks. We can conclude that while some hedging via derivatives occurs, it is mostly limited to small exposures taken by relatively small banks with little trading business. 


\section{References}

Acharya, Viral, Pedersen, Lasse, Thomas Phillipon, and Matt Richardson 2010. "Measuring Systemic Risk." Working Paper, NYU.

Acharya, Viral, Matt Richardson, Stijn van Nieuwerburgh, and L. White 2011. "Guaranteed to Fail: Freddie, Fennie, and the Debacle of U.S. Mortgage Finance." Princeton University Press.

Adrian, Tobias and Nina Boyarchenko 2012. " Intermediary Leverage Cycles and Financial Stability". Federal Reserve Bank of New York Staff Reports, Number 567.

Adrian, Tobias and Hyun Song Shin 2011. "Procyclical Leverage and Value at Risk." Working Paper, Princeton.

Allen, Franklin 2001. "Do Financial Institutions Matter?" Journal of Finance, 56, pp. 1165-1175.

Ang, Andrew and Monika Piazzesi 2003. "A No-Arbitrage Vector Regression of Term Structure Dynamics with Macroeconomic and Latent Variables." Journal of Monetary Economics, 50, pp. 745-787.

Brunnermeier, Markus, Gary Gorton, and Arvind Krishnamurthy 2012. "Risk Topography." NBER Macro Annual 2011.

Chernenko, Sergey and Faulkender, Michael 2011. "The Two Sides of Derivatives Usage: Hedging and Speculating with Interest Rate Swaps." Journal of Financial and Quantitative Analysis (46), pp. 1727-1754.

Duffie, Darrell 2012. "Systemic Risk Exposures: A 10-by-10-by-10 Approach." Systemic Risk and Macro Modeling, Markus Brunnermeier and Arvind Krishnamurthy, editors.

Duffie, Darrell and Kenneth Singleton 1999. "Modeling Term Structures of Defaultable Bonds." Review of Financial Studies 12, pp. 687-720.

English, William B., Skander J. Van den Heuvel, and Egon Zakrajsek 2012. "Interest Rate Risk and Bank Equity Valuations." Working Paper, Federal Reserve Board.

Gorton, Gary and Richard Rosen 1995. "Banks and Derivatives". NBER Macroannual 1995, pp. 299-349.

Flannery, Mark J. and Christopher M. James 1984a. "The Effect of Interest Rate Changes on the Common Stock Returns of Financial Institutions." Journal of Finance 39, 4, pp. 1141-1153.

Flannery, Mark J. and Christopher M. James 1984b. "Market Evidence on the Effective Maturity of Bank Assets and Liabilities." Journal of Money, Credit and Banking, 16, pp. 435-445.

Flannery, Mark J., Allaudeen Hammed and Richard H. Haries 1997. "Asset Pricing, time-varying risk premia and interest rate risk." Journal of Banking and Finance 21, pp. 315-335. 
Greenlaw, David, Anil Kashyap, Hyun Song Shing and Kermit Schoenholtz 2012. "Stressed Out: Macroprudential Principles for Stress Testing", U.S. Monetary Policy Forum Report No.5, Initiative on Global Markets, University of Chicago Booth School of Business.

He, Zhiguo, In Gu Khang, and Arvind Krishnamurthy 2010. "Balance-Sheet Adjustments during the 2008 Crisis." IMF Economic Review 1, 118-156.

Hentschel, Ludger and S.P. Kothari 2001. "Are Corporations Reducing or Taking Risks with Derivatives?" Journal of Financial and Quantitative Analysis 36, pp. 93-118.

Hirtle, Beverly J. 1997. "Derivatives, Portfolio Composition, and Bank Holding Company Interest Rate Risk Exposure." Journal of Financial Services Research 12, pp. 243-266.

Jarrow, Robert, Haitao Li, Sheen Liu, and Chunchi Wu 2010. "Reduced-form valuation of callable corporate bonds: Theory and Evidence." Journal of Financial Economics 95, pp. 227-248.

Jermann, Urban and Vivian Y. Yue 2012. "Interest Rate Swaps and Corporate Default." Working Paper, Wharton.

Kelly, Bryan, Hanno Lustig and Stijn van Nieuwerburgh 2011. "Too-Systemic-To-Fail: What Option Markets Imply About Sector-wide Government Guarantees." NBER Working Paper 17149.

Landier, Augustin, David Sraer, and David Thesmar 2013. "Banks Exposure to Interest Rate Risk and the Transmission of Monetary Policy." NBER Working Paper 18857.

Lustig, Hanno, Chris Sleet and Sevin Yeltekin 2008. "Fiscal hedging with nominal assets." Journal of Monetary Economics 55, pp. 710-727.

Piazzesi, Monika and Martin Schneider 2010. "Interest Rate Risk in Credit Markets". American Economic Review 100 (2), pp. 579-584.

Venkatachalam, Mohan 1996. "Value-relevance of banks' derivatives disclosures." Journal of Accounting and Economics 22, pp. 327-355. 


\section{Appendix}

\section{Details on balance sheet items}

Figure 12 shows the Schedule HC-B for Securities entry in the balance sheet of Table 1. The schedule illustrates the asset detail available for each bank.

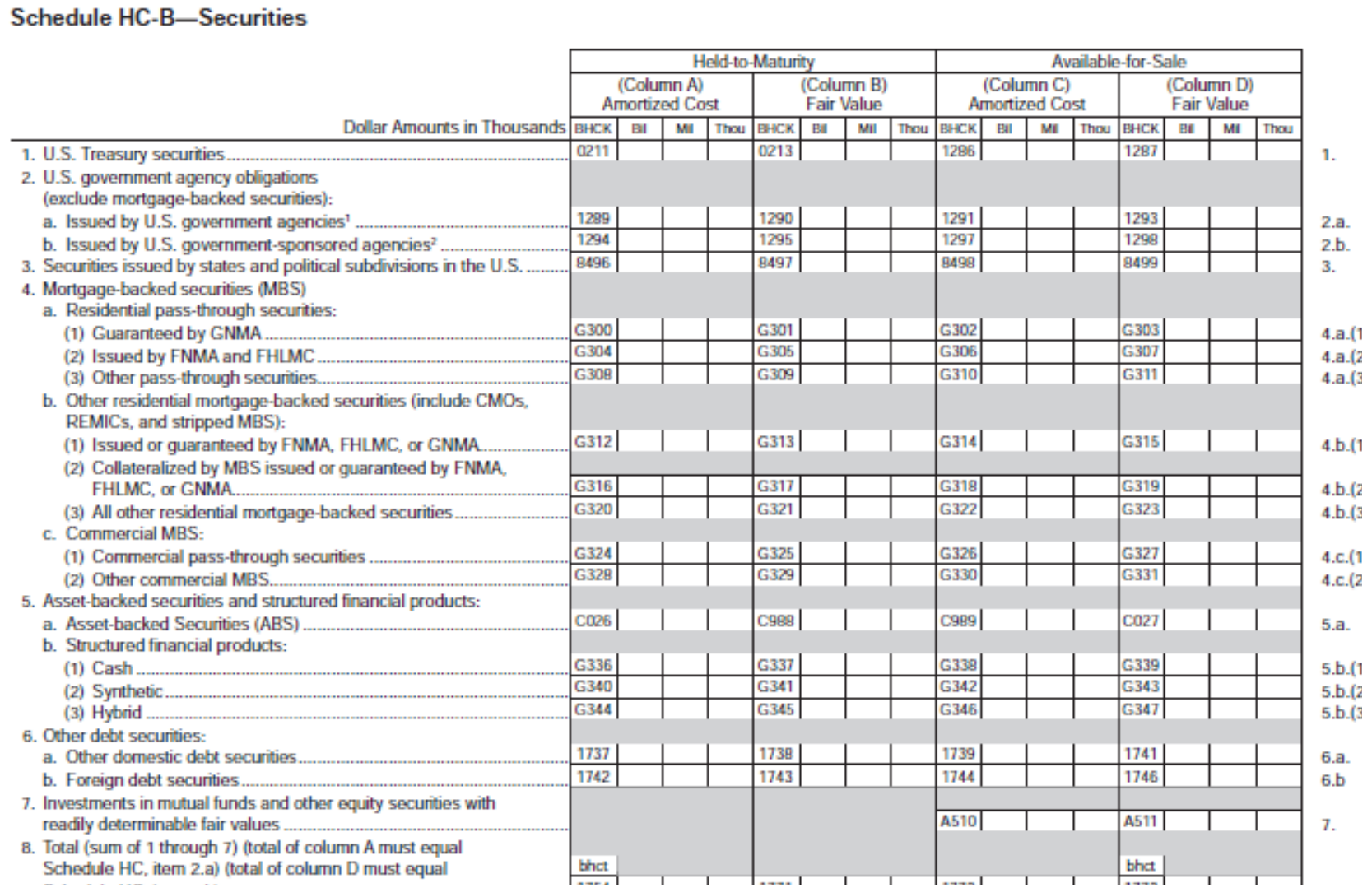

Figure 12: HB-C Schedule for Securities.

\section{Details on derivatives estimation}

This appendix justifies the approximation (5). We first sum up contributions to gross fair value from individual positions $(\phi, m, s)$ to obtain a decomposition analogous to (3). If bid-ask spreads are small, then the sign of a position with nonzero value is driven by the mid-market rate alone. We thus assume that positions are such that $F_{t}(s-z, m)>0$ if and only if $-F_{t}(s+z, m)<0$ and that $F_{t}(s-z, m)<0$ if and only if $-F_{t}(s-z, m)<0$. 
Summing again over all individual positions, we now obtain

$$
G V_{t}=\sum_{\phi, m} N_{t}^{\phi, m}\left|F_{t}\left(\bar{s}_{t}, m\right)\right|+\sum_{m}\left|N_{t}^{1, m}-N_{t}^{-1, m}\right| z_{t}^{m} C_{t}^{(m)} .
$$

The first sum collects all gross positions that would arise if all trades had taken place at mid-market rates. The second term again reflects bid-ask spreads. It is typically an order of magnitude smaller than the first and negligible in our analysis.

We now apply the two assumptions stated in the text. The first assumption is that $\bar{s}^{1, m}=\bar{s}^{-1, m}$ for all $m$ and there exist weights $\hat{w}_{t}^{m}$ such that $N_{t}^{\phi, m}=\hat{w}_{t}^{m} \hat{N}_{t}^{\phi}$. The second assumption is that $\sum_{m} w_{t}^{m} F_{t}\left(\bar{s}_{t}^{m}, m\right) \approx F_{t}\left(\bar{s}_{t}, \bar{m}_{t}\right)$. Substituting into (1) we have

$$
G V_{t}=\hat{N}_{t}\left|F_{t}\left(\bar{s}_{t}, \bar{m}\right)\right|+\frac{N_{t}^{1}-N_{t}^{-1}}{N_{t}} F V_{t}^{r e n t}
$$

To arrive at (5). we use the fact that the second term is an order of magnitude smaller than the first provided that bid-ask spread are as small as in our data. To see this, note first that the valuation factor $F_{t}$ is of the same magnitude as an interest rate. The first term is thus essentially multiplies total notionals by an interest rate. In contrast, the second term multiplies a fraction of total notionals by $z_{t}^{m} C_{t}^{(m)}$, which is less than one basis point. 